\title{
Signaling a change in cue-outcome relations in human associative learning
}

\author{
OSKAR PINEÑO and RALPH R. MILLER \\ State University of New York, Binghamton, New York
}

\begin{abstract}
In three experiments, we assessed the role of signals for changes in the consequences of cues as a potential account of the renewal effect. Experiment 1 showed recovery of responding following extinction when acquisition, extinction, and test phases occurred in different contexts. In addition, extinction treatment in multiple contexts attenuated context-induced response recovery. In Experiment 2, we used presentations of an extraneous stimulus (ES), instead of context shifts, and found that responding recovered from extinction only when the ES was presented both between acquisition and extinction and between extinction and test. In Experiment 3, we used a reversal learning design in which, during training, two cues were first paired with different outcomes, then paired with the alternative outcomes, and finally paired again with the original outcomes. In this experiment, presentation, just prior to testing, of an ES that had previously been presented between the different phases produced an expectation of reversal in the meaning of the cues.
\end{abstract}

Learning to predict the occurrence of certain events in the environment is essential for survival. Humans, as well as nonhuman animals, learn when and where reinforcers such as food and water will be available and adapt their behavior to improve the likelihood of obtaining these substances. However, people live in dynamic environments, in which an event that previously signaled an appetitive outcome can cease to be a reliable predictor of that appealing event or can become a predictor of an aversive event. In such a case, learning a change in the predictive value of an event is as important for one's well-being as learning to produce the original response was previously. Making this situation even more complex, people can learn that the same cue can signal different outcomes in different situations. For example, we can learn that a professor is serious and distant in the lecture hall but warm and friendly at a dinner, or we can learn that a beer tastes good on tap in a bar, but not when drunk from a bottle at home.

This article is concerned with how humans learn to respond to a cue that has been paired with different outcomes in separate treatment phases according to their expectations concerning the meaning of the cue in different situations. Specifically, this article focuses on the renewal effect, extensively studied by Bouton and his colleagues (e.g., Bouton \& Bolles, 1979; Bouton \& King, 1983; Bouton \& Ricker, 1994) and more recently investi-

O.P. was supported by a postdoctoral fellowship from the Spanish Ministry of Education (Ref. EX2002-0739). We thank Jeffrey Amundson, Tom Beckers, Steven Stout, Gonzalo Urcelay, Kouji Urushihara, and Daniel Wheeler for their insightful comments on an earlier version of this article, as well as Danielle Gutter, Jamie Francis, and Leanne Scally for their assistance in running the experiments. Correspondence concerning this article should be addressed to R. R. Miller, Department of Psychology, SUNY Binghamton, Binghamton, NY 13902-6000 (email:rmiller@binghamton.edu). gated by other researchers, with both nonhuman animals (e.g., Harris, Jones, Bailey, \& Westbrook, 2000) and humans (e.g., García-Gutiérrez \& Rosas, 2003; Rosas, Vila, Lugo, \& López, 2001). The renewal effect consists of the recovery of responding to a cue that has undergone extinction when the cue is tested outside of the extinction context. Initial pairings of a cue with an outcome (i.e., cue-outcome trials) encourage the formation and strengthening of a response to the cue, whereas the subsequent presentation of the cue alone (i.e., cue-no-outcome trials) results in a progressive decrease in the frequency and/or strength of that response, which is called extinction. However, when the cue is later presented in a context different from that in which the extinction treatment occurred, responding to the cue tends to recover or, in other words, is renewed.

The discovery of the renewal effect has challenged many traditional theories of learning (e.g., Mackintosh, 1975; Pearce \& Hall, 1980; Rescorla \& Wagner, 1972; Wagner, 1981), as well as some more recent models (e.g., Dickinson \& Burke, 1996; Miller \& Matzel, 1988; Van Hamme \& Wasserman, 1994). According to some of these models (i.e., Mackintosh, 1975; Rescorla \& Wagner, 1972; Van Hamme \& Wasserman, 1994), extinction of responding occurs due to the weakening of the excitatory cue-outcome association, which was previously developed during acquisition. In other words, extinction treatment produces an unlearning of the cue-outcome association. As a consequence, these unlearning models predict that shifting the context between extinction and testing should not reverse the extinction process.

Other models reject the view of extinction as unlearning but differ in their explanations for the phenomenon. Whereas for Wagner (1981) and Dickinson and Burke (1996), extinction is due to the formation of an inhibitory cue-outcome association that interferes with the excitatory cue-outcome association, Pearce and Hall (1980) attrib- 
uted extinction to the formation of an excitatory cue-nooutcome association that interferes with the expression of the excitatory cue-outcome association. Miller and Matzel (1988) adopted a more radical position and denied the very existence of inhibitory (or excitatory cue-no-outcome) associations. In the framework of their comparator hypothesis, extinction is viewed as resulting in part from a strengthening of the cue-context association during the cue-alone trials, which interferes with responding to the cue during testing. Although in the latter models the cue-outcome association remains intact after extinction, none of these models is able to explain why responding to the cue recovers as a result of changing the context between extinction and testing. Therefore, recent models of learning, as well as traditional ones, are unable to explain the renewal effect. The renewal effect, as well as other demonstrations of response recovery following extinction, such as spontaneous recovery from extinction (Pavlov, 1927), have been largely ignored by most models of learning.

Bouton (1993), however, has provided a theoretical framework in which the recovery of responding to a cue following extinction can be understood. According to Bouton, effects such as extinction and counterconditioning are based on the formation of an inhibitory cue-outcome (or excitatory cue-no-outcome) association that interferes with retrieval from memory of the excitatory cue-outcome association. Bouton's theory, also known as the retrieval failure theory, explains extinction and counterconditioning as effects of differential retrieval of opposing associations. In this framework, when a cue is paired with different outcomes (e.g., with the target outcome and no outcome), the meaning of the cue becomes ambiguous. According to this theory, the context serves to disambiguate the meaning of the cue. In Bouton's view, retrieval of inhibitory associations is primed (i.e., facilitated) by the context in which they are acquired and, thus, become context dependent. That is, in order for an inhibitory association to be retrieved from memory, the context in which it was trained must be present. When the context is not present, the inhibitory cue-outcome association is poorly retrieved and, thus, cannot interfere with retrieval of the excitatory cue-outcome association. This absence of interference allows a stronger behavioral expression of the excitatory association. Moreover, Bouton treats both the physical environment and time as contexts. When the spatial context is changed from extinction to test, a renewal of responding is said to occur, whereas changing the temporal context from extinction to test (i.e., interpolating a time interval between training and test) produces the spontaneous recovery effect.

Several experimental designs have been used in the study of renewal. The most effective of these manipulations involves training and testing the excitatory cueoutcome association in one context (i.e., Context A) and giving the extinction trials in a different context (i.e., Context B). This manipulation, known as the ABA design, produces a strong and reliable renewal effect (e.g., Bouton $\&$ King, 1983). Responding to a cue following extinction can also be strongly renewed by performing the acquisition, extinction, and test phases in different contexts (i.e., the ABC design; e.g., Bouton \& Bolles, 1979). Finally, $\mathrm{AAB}$ renewal (i.e., performing acquisition and extinction in the same context, different from that of testing) has also been demonstrated (Bouton \& Ricker, 1994). However, as was acknowledged by Bouton and Ricker, this manipulation seems to be the weakest in producing response recovery.

All of these renewal manipulations have in common the testing of the cue outside of its extinction context, which supports Bouton's (1993) views concerning the contextual dependency of the inhibitory cue-outcome association. However, the question arises: Why is retrieval of the inhibitory association dependent on its training context, whereas retrieval of the excitatory association is relatively free from this constraint? One possibility is that there is something intrinsically different in the nature of these associations and that organisms have evolved or developed so that learning mechanisms conditionalize the retrieval of inhibitory associations to the presence of contextual cues because they are usually less important for survival, relative to excitatory associations (see Bouton, 1994, for a detailed discussion). A more concrete explanation is based on the fact that the inhibitory association is the second-learned association in extinction experiments (Bouton, 1997; Bouton \& Nelson, 1998). During the initial acquisition phase, the cue has unequivocal meaning for the animal: The cue is exclusively a predictor of the outcome. However, during extinction the cue becomes ambiguous (i.e., the cue now predicts both the presence and the absence of the outcome); therefore, the animal now needs a signal to disambiguate the meaning of the cue. Thus, the second-learned association is encoded with the contextual cues that accompany it, whereas the first-learned association is encoded independently of its training context. When the context is changed from acquisition to extinction, as occurs in the $\mathrm{ABA}$ and $\mathrm{ABC}$ designs, the presence of Context $\mathrm{B}$ provides information about the new meaning of the cue (i.e., the inhibitory cue-outcome association), and the retrieval of the inhibitory cue-outcome association becomes conditionalized to the presence of Context B.

This explanation of the $\mathrm{ABA}$ and $\mathrm{ABC}$ renewal by Bouton (1993) can also explain why the AAB renewal manipulation often produces weak response recovery. According to Bouton and Ricker (1994), AAB renewal is explained by assuming that the context switch performed prior to testing more strongly disrupts retrieval of the inhibitory association than retrieval of the excitatory association. However, because in the AAB renewal design the context is not switched between acquisition and extinction (i.e., when the meaning of the cue becomes ambiguous), the context becomes a poor priming stimulus for either the excitatory association or the inhibitory association.

Bouton's $(1993,1997)$ two explanations of why these different contextual manipulations produce a recovery of responding at test are parsimonious. However, one as- 
pect that has been ignored in his models of renewal is that a change of context between acquisition and extinction in the $\mathrm{ABA}$ and $\mathrm{ABC}$ renewal designs always precedes the change in the cue-outcome relation. That is, the animal is moved from Context A to Context B before the cue changes its meaning. This potentially allows the animal to learn not only that the cue has a new meaning in the new context, but also that the change of context itself precedes a change of the cue-outcome relation. If the animal learns this predictive relation between the change of context and the reversal of the reinforcement contingency of the cue between acquisition and extinction, it is possible for the animal to anticipate another change in the meaning of the cue if the context is changed immediately prior to testing. In this case, because the cue was paired with no outcome during extinction, the animal could anticipate the cue to be newly paired with the outcome during testing. That is, changes in context per se could signal a change in reinforcement contingencies.

This alternative and potentially complementary explanation of $\mathrm{ABA}$ and $\mathrm{ABC}$ renewal helps to explain the weak response recovery observed in the $\mathrm{AAB}$ renewal. In this case, because both the acquisition and the extinction phases occur in the same context, the animal cannot learn to predict the change of the cue-outcome relation on the basis of the contextual change. Thus, when the context is switched between extinction and testing, the animal is unable to anticipate any change in the cue-outcome relation, and responding is not (or is weakly) recovered. Consequently, AAB renewal likely depends only on specific contexts having modulatory roles for extinction (i.e., Bouton's hypothesis), whereas $\mathrm{ABA}$ and $\mathrm{ABC}$ renewal benefit from this plus the signaling role of a change in context. This account of the ABA and ABC renewal offers a straightforward explanation of recent findings by Gunther, Denniston, and Miller (1998) and Chelonis, Calton, Hart, and Schachtman (1999). These authors observed that both the ABC (Gunther et al., 1998) and the ABA (Chelonis et al., 1999) renewal can be attenuated by performing extinction in multiple contexts. For example, Gunther et al. gave extinction trials to one group of rats in one context and to another group in three different contexts. The results indicated that exposing the rats to the cue-alone trials in three different contexts attenuated renewal of responding when the cue was tested in a novel context. In this condition, the animals are also exposed twice to changes in the context without any subsequent change in the meaning of the cue, potentially disconfirming any previous learning that context change predicts a change in the cue-outcome relation. Therefore, when the context is changed immediately before testing, the animal does not expect this change to be followed by any change in the meaning of the cue, which results in an attenuation of the renewal effect. However, as was suggested by Gunther et al., Bouton's (1993) theory might be extended to explain their results by assuming that performing extinction in multiple contexts increases the probability that the test context will contain more stimulus elements able to prime the memory of the inhibitory cue-outcome association. In other words, the more contexts that are present during extinction, the more likely it is that the test context will resemble the contexts of extinction and, thus, the stronger will be the retrieval of the inhibitory association.

The present the series of experiments was designed to contrast Bouton's $(1993,1997)$ views concerning renewal of responding with our alternative view, which will be referred as the signal of a change in the cue-outcome relation (signal) hypothesis. These experiments were performed using a behavioral preparation for the study of predictive learning by humans that had previously been used by Pineño and his colleagues (Escobar, Pineño, \& Matute, 2002; Pineño \& Matute, 2000; Pineño, Ortega, \& Matute, 2000). In our first experiment, we attempted to replicate the basic finding of Gunther et al. (1998), which had been observed in a classical conditioning preparation with rats, that $\mathrm{ABC}$ renewal was attenuated by performing extinction in three different contexts. In Experiment 2, we extended the results of Experiment 1 to a different manipulation, the presentation of an extraneous stimulus (ES) between phases of treatment. In Experiment 3 , we used a reversal learning design with four phases-acquisition, extinction, reacquisition, and test - to further test the extent to which changing contexts can serve as a signal for a change in reinforcement contingencies.

\section{EXPERIMENT 1}

In Experiment 1, we assessed whether our preparation would show an $\mathrm{ABC}$ renewal effect and, if so, whether extinction in multiple contexts would attenuate the renewal effect. We chose to replicate, this time with human participants, the results of Gunther et al. (1998) with an $\mathrm{ABC}$ design, instead of an ABA design (Chelonis et al., 1999), because $A B C$ renewal is less subject to alternative explanations than is ABA renewal. For example, ABA renewal could be explained by traditional associative models (e.g., Rescorla \& Wagner, 1972), as summation during testing of a residual excitatory associative strength of the cue following extinction with the associative strength of Context A, which did not undergo extinction. Configural models, such as that of Pearce (1987), could explain ABA renewal on the basis of the formation of different cue-context configurations, one of them always followed by the outcome (i.e., $[\mathrm{X}+$ Context $\mathrm{A}]$-outcome), and the other never being followed by the outcome (i.e., $[\mathrm{X}+$ Context B]-no-outcome). Testing Cue $\mathrm{X}$ in a novel context (i.e., the $\mathrm{ABC}$ design) avoids these alternative explanations because (1) the test context should not have any appreciable associative strength (i.e., Rescorla \& Wagner, 1972) and (2) the presentation of the cue in Context C avoids reinstatement of any X + Context A configuration (i.e., Pearce, 1987).

Three groups were given acquisition and extinction training with a cue, $X$, followed by test trials. For one of 
the groups, all of these phases took place in the same context (i.e., Group AET, each letter in the name of the group denoting a successive phase, acquisition [A], extinction [E], and test $[\mathrm{T}]$ ). Group A-E-T was given each phase in a different context (the dash [-] represents a contextual switch being performed). Finally, Group A-EE-E-T was exposed to a context switch, not only between phases (like Group A-E-T), but also during the extinction phase. If the present experiment replicates the results of Gunther et al. (1998), responding to Cue X at test should be stronger in Group A-E-T than in groups AET and A-E-E-E-T, thereby showing evidence of an $\mathrm{ABC}$ renewal (i.e., Group A-E-T vs. Group AET) and of attenuation of the $\mathrm{ABC}$ renewal by performing extinction training in multiple contexts (i.e., Group A-E-T vs. Group A-E-E-E-T).

\section{Method \\ Participants and Apparatus}

The participants were 38 students ( 12 men and 26 women, with a mean age of 18.6 years $[S E M=0.16]$ ) from an introductory psychology course at SUNY-Binghamton, who participated in this experiment in partial fulfillment of a course requirement. The participants were assigned to one of three groups, resulting in 13 participants in Groups AET and A-E-T and 12 in Group A-E-E-E-T. The experiment was conducted using personal computers, housed in individual cubicles.

\section{Design and Procedure}

Table 1 summarizes the design for this experiment. Except for contexts, all the groups were exposed to identical treatment with the cues in the different phases. During the acquisition phase, all the groups were given 15 presentations of Cue $\mathrm{X}$ always followed by Outcome 1 (O1; i.e., X-O1), interspersed with 15 presentations of Cue Y always followed by Outcome 2 (O2; i.e., Y-O2). During the acquisition phase, $\mathrm{X}-\mathrm{O} 1$ and $\mathrm{Y}-\mathrm{O} 2$ trials were presented according to the following pseudorandom sequence: $\mathrm{X}-\mathrm{O} 1, \mathrm{X}-\mathrm{O} 1, \mathrm{Y}-\mathrm{O} 2$, $\mathrm{X}-\mathrm{O} 1, \mathrm{X}-\mathrm{O} 1, \mathrm{Y}-\mathrm{O} 2, \mathrm{Y}-\mathrm{O} 2, \mathrm{X}-\mathrm{O} 1, \mathrm{Y}-\mathrm{O} 2, \mathrm{Y}-\mathrm{O} 2, \mathrm{X}-\mathrm{O} 1, \mathrm{Y}-\mathrm{O} 2$, $\mathrm{X}-\mathrm{O} 1, \mathrm{Y}-\mathrm{O} 2, \mathrm{Y}-\mathrm{O} 2, \mathrm{X}-\mathrm{O} 1, \mathrm{Y}-\mathrm{O} 2, \mathrm{X}-\mathrm{O} 1, \mathrm{X}-\mathrm{O} 1, \mathrm{Y}-\mathrm{O} 2, \mathrm{X}-\mathrm{O} 1$, $\mathrm{X}-\mathrm{O} 1, \mathrm{Y}-\mathrm{O} 2, \mathrm{X}-\mathrm{O} 1, \mathrm{X}-\mathrm{O} 1, \mathrm{Y}-\mathrm{O} 2, \mathrm{Y}-\mathrm{O} 2, \mathrm{X}-\mathrm{O} 1, \mathrm{Y}-\mathrm{O} 2, \mathrm{Y}-\mathrm{O} 2$. Presentations of $\mathrm{Y}-\mathrm{O} 2$ trials were included because previous experiments performed with this task (e.g., Pineño et al., 2000) had shown that they are necessary in order to minimize generalization of responding to any new cue or to any cue in a new context. Also, in previous experiments in which this task was used, when only
$\mathrm{X}-\mathrm{O} 1$ trials were given, participants tended to strongly respond during the intertrial intervals in anticipation of the next presentation of X. By interpolating $\mathrm{Y}-\mathrm{O} 2$ trials during training of the $\mathrm{X}-\mathrm{O} 1$ association, we expected responding to be more dependent on the presence of Cue X.

During the extinction phase, all the groups were given 15 presentations of Cue X followed by Outcome 3 (O3; i.e., $\mathrm{X}-\mathrm{O} 3$ ). O1 was a rewarding outcome, $\mathrm{O} 2$ was a punishing outcome, and $\mathrm{O} 3$ was a neutral outcome with no positive or negative value. Hence, $\mathrm{O} 3$ was equivalent to a nonreinforcement condition, and here, a cue- $\mathrm{O} 3$ trial is treated as equivalent to an extinction trial. Finally, all the groups received 5 presentations of $\mathrm{X}$ followed by $\mathrm{O} 3$ during the test phase.

In Group AET, all the phases took place in Context A. In Group $\mathrm{A}-\mathrm{E}-\mathrm{T}$, the acquisition, extinction, and test phases took place in Contexts A, B, and F, respectively. ${ }^{1}$ Thus, in this group, the transition between different phases was signaled by a context change. Finally, in Group A-E-E-E-T, as in Group A-E-T, the acquisition and test phases took place in Contexts A and F, respectively. However, in this group, the extinction phase was given in three different contexts (i.e., Contexts B, C, and D), instead of in only one context (i.e., Context B), as occurred in Group A-E-T. Specifically, in Group A-E-E-E-T, each block of $5 \mathrm{X}-\mathrm{O} 3$ trials (out of the 15 trials of extinction) took place in a different context. Other than the contextual changes in the designated groups, no interruptions occurred between the different phases of the experiment.

The preparation that we used in this experiment ${ }^{2}$ was an adaptation to Borland Visual $\mathrm{C}++$ of the preparation previously used by Pineño et al. (2000). In the present preparation, the task of the participants was to help a group of refugees escape from a war zone in trucks. The dependent variable was the number of refugees placed in the trucks during cue presentations. At the beginning of the experiment, the participants were shown the following screens of instructions:

\section{Screen 1}

Imagine that you are a soldier for the United Nations. Your mission consists of rescuing a group of refugees that are hidden in a ramshackle building. The enemy has detected them and has sent forces to destroy the building. But the refugees rely on your cunning to escape the danger zone before that happens.

You have several trucks to rescue the refugees, and you have to place them in those trucks. In order to place people in the trucks, you must click with the mouse on the button labeled as "Place people in the truck," so that one person per click is placed in a truck.

If you rescue a number of people on a given trip, they will arrive to their destination alive, and you will be rewarded with a point for each person. You must gain as many points as possible.

Table 1

Design of Experiment 1

\begin{tabular}{|c|c|c|c|}
\hline Group & Acquisition & Extinction & Test \\
\hline $\begin{array}{l}\text { AET } \\
\text { A-E-T } \\
\text { A-E-E-E-T }\end{array}$ & $\begin{array}{l}(15 \mathrm{X} \rightarrow \mathrm{O} 1 / 15 \mathrm{Y} \rightarrow \mathrm{O} 2) \text { in } \mathrm{A} \\
(15 \mathrm{X} \rightarrow \mathrm{O} 1 / 15 \mathrm{Y} \rightarrow \mathrm{O} 2) \text { in } \mathrm{A} \\
(15 \mathrm{X} \rightarrow \mathrm{O} 1 / 15 \mathrm{Y} \rightarrow \mathrm{O} 2) \text { in } \mathrm{A}\end{array}$ & $\begin{array}{l}(15 \mathrm{X} \rightarrow \mathrm{O} 3) \text { in } \mathrm{A} \\
(15 \mathrm{X} \rightarrow \mathrm{O} 3) \text { in } \mathrm{B} \\
(5 \mathrm{X} \rightarrow \mathrm{O} 3) \text { in } \mathrm{B} \\
(5 \mathrm{X} \rightarrow \mathrm{O} 3) \text { in } \mathrm{C} \\
(5 \mathrm{X} \rightarrow \mathrm{O} 3) \text { in } \mathrm{D}\end{array}$ & $\begin{array}{l}(5 X \rightarrow O 3) \text { in } A \\
(5 X \rightarrow O 3) \text { in } F \\
(5 X \rightarrow O 3) \text { in } F\end{array}$ \\
\hline
\end{tabular}

Note-The letters in the group names refer to the different phases (i.e., acquisition, extinction, and test), and the dash (-) denotes the moments in which a context change was performed. $\mathrm{X}$ was the target cue, and $\mathrm{Y}$ was introduced to prevent strong stimulus generalization. Presentations of $\mathrm{X}$ were followed by Outcome 1 (O1) during the acquisition phase and by Outcome $3(\mathrm{O} 3)$ during the extinction phase. Presentations of $\mathrm{Y}$ were always followed by Outcome $2(\mathrm{O} 2)$. Trial types separated by a slash were interspersed. The numbers denote the number of presentations of each trial type in each phase, whereas the letters A, B, C, D, and F denote the different contexts used in the experiment. 


\section{Screen 2}

But your mission will not be as simple as it seems. The enemy knows of your movements and could have placed deadly mines on the road. If the truck hits a mine, it will explode, and the passengers will die. Each dead passenger will count as one negative point for you.

Fortunately, the colored lights on the spy radio will indicate the state of the road. The lights can indicate that:

a) The road will be free of mines. $\rightarrow$ The occupants of the truck will be liberated. $\rightarrow$ You will gain points.

b) The road will be mined. $\rightarrow$ The occupants of the truck will die. $\rightarrow$ You will lose points.

c) There are no mines, but the road is closed. $\rightarrow$ The occupants of the truck will neither die nor be liberated. $\rightarrow$ You will neither gain nor lose points: You will maintain your previous score.

\section{Screen 3}

At first, you will not know what each colored light on the spy radio means. However, as you gain experience with them, you will learn their meanings.

Thus, we recommend that you:

a) Place more people in the truck as you become more certain that the road that you are on is free of mines.

b) Place fewer people in the truck the more certain you are that the road is mined.

Finally, it is important to know that your mission may occur in several different places. Please pay attention to the message that indicates the place in which you are.

These instructions are an English translation of the Spanish instructions used by Pineño et al. (2000) in their experiments, the only difference being that in the present experiments, we removed from the instructions any explicit mention that the meaning of the cues depended on the context. We did this to minimize the possibility of our results being due to demands of the instructions, instead of merely the different contextual manipulations performed during treatment.

The top of the screen showed a spy radio that consisted of a gray horizontal panel on which six colored lights could be presented. Cues $\mathrm{X}$ and $\mathrm{Y}$ were blue and yellow lights on the spy radio, counterbalanced. In this experiment, on each trial, a randomly chosen light position was illuminated with the color of that trial's cue. Cue durations were $5 \mathrm{sec}$. During the 5 -sec intertrial intervals, all the lights were turned off. While a light was on, each response (i.e., clicking with the mouse on a screen button labeled as "Place people in the truck") placed one refugee in the truck. The number of refugees loaded in the truck during the cue was reported in a box on the screen, this number being immediately updated after each response. On each trial, the termination of the cue coincided with the presentation of the outcome.

The $\mathrm{O} 1$ consisted of $(1)$ the message "[ $N]$ refugees safe!!!" (with $[N]$ being the number of refugees placed in the truck during the cue presentation) and (2) the participant's gaining one point for each refugee who was assisted. The $\mathrm{O} 1$ message was accompanied by the presentation of a happy face icon. The $\mathrm{O} 2$ consisted of (1) the message " $[N]$ refugees have died!!!" and (2) the participant's losing one point for each refugee who died in the truck. The $\mathrm{O} 2$ message was accompanied by the presentation of a tombstone icon. The O3 consisted of (1) the message "Road closed" and (2) the participant's maintaining the previous score. The $\mathrm{O} 3$ message was accompanied by the presentation of a stop sign icon. The outcome message remained on the screen for $5 \mathrm{sec}$.

Thus, the number of refugees that the participants risked by placing them in the truck was our dependent variable. Presumably, the more certain the participants were that the trip would be successful (i.e., O1), the greater number of refugees they would take, whereas the more certain they were that the truck would explode, the smaller number of refugees they would take (i.e., O2). In addition, because introducing refugees did not have any effect on the score when $\mathrm{O} 3$ followed the cue, we expected the participants to gradually extinguish their responding when the cue was followed by $\mathrm{O} 3$.

A score panel on the screen showed the number of people that the participant had placed in the truck on each trial, and that number remained visible until the end of the outcome message. Clicks on the "Place people in the truck" button that occurred while the outcome message was present had no consequences. At the termination of the outcome message, this panel was reset to 0 . Responses that occurred during the intertrial intervals had no consequences and were not reflected on the panel.

The contexts used in the experiment consisted of names of fictitious towns, which were presented together with pictures of distinctive ramshackle buildings; the name of each fictitious town was always associated with the same picture of a ramshackle building. Contexts $\mathrm{A}$ and $\mathrm{F}$ consisted of the fictitious towns Bow Town and Smithburgh, counterbalanced. Contexts B, C, and D consisted of the fictitious towns Pittdown, Junction City, and Centerville, counterbalanced. The name of the town and its corresponding picture were shown horizontally during both trials and intertrial intervals in the middle of the screen just below the cue light panel. All the pictures of the buildings were $200 \times 160$ pixels $(\mathrm{w} \times \mathrm{h})$, and they were always presented to the right of the name of the town.

\section{Preanalysis Treatment of the Data}

Data selection criteria. Two data selection criteria were used in order to ensure that the participants were paying attention to the task. The first criterion was that the number of responses given during the last block of five trials with $\mathrm{X}-\mathrm{O} 1$ in the acquisition phase had to be higher than the number of responses given during the last block of five trials with $\mathrm{Y}-\mathrm{O} 2$ in the acquisition phase. Therefore, this criterion eliminated those participants who did not learn to discriminate between the different cues presented in Phase 1. The second criterion was that the number of responses given during the last block of five trials with $\mathrm{X}-\mathrm{O} 1$ in the acquisition phase had to be higher than the number of responses given during the last block of five trials with $\mathrm{X}-\mathrm{O} 3$ in the extinction phase. Therefore, this criterion eliminated those participants who did not extinguish responding during treatment with the $\mathrm{X}-\mathrm{O} 3$ trials. As a result of these two criteria, no participant was eliminated from this experiment.

Facilitation ratio. Previous pilot studies performed in our laboratory showed a large variance in the number of responses given by the different participants during the extinction phase. These withingroup differences could be due to our use of a neutral outcome (i.e., O3) during the extinction phase: $\mathrm{On} \mathrm{X}-\mathrm{O} 3$ trials, responses performed by the participants were not rewarded with points, but neither were they punished with the loss of points. Seemingly, some of the participants decided to gradually decrease responding during the $\mathrm{X}-\mathrm{O} 3$ trials (presumably because the responses no longer yielded points), whereas other participants partially maintained responding (presumably because they remembered that responding in the presence of Cue X had previously been rewarded and no points had been lost by responding). These different baselines of responding during extinction within each group raise problems for the present series of experiments, because our concern was recovery of responding during testing. Because the participants differed in their number of responses to the target cue, $\mathrm{X}$, at the end of the extinction phase, an identical number of responses during testing could reflect either responding appropriate to the extinction phase (i.e., a maintenance of the baseline of responding) or strong recovery of responding.

In order to eliminate the influence of different baselines of responding among the participants, a facilitation ratio (FR) was used. The FR was calculated as FR $=A /(A+B)$, in which $A$ was the number of responses to the cue during the block of five test trials and $B$ was the number of responses to the cue during the block of five tri- 
Table 2

Mean Number of Responses to $X$ in Experiments 1 and 2

\begin{tabular}{|c|c|c|c|c|c|c|}
\hline \multirow[b]{2}{*}{ Group } & \multicolumn{2}{|c|}{ Acquisition } & \multicolumn{2}{|c|}{ Extinction } & \multicolumn{2}{|c|}{ Test } \\
\hline & $M$ & SEM & $M$ & $S E M$ & $M$ & $S E M$ \\
\hline \multicolumn{7}{|c|}{ Experiment 1} \\
\hline AET & 26.81 & 1.00 & 5.93 & 2.14 & 3.69 & 1.96 \\
\hline $\mathrm{A}-\mathrm{E}-\mathrm{T}$ & 27.38 & 1.72 & 2.20 & 1.88 & 3.63 & 2.10 \\
\hline A-E-E-E-T & 29.38 & 2.20 & 1.30 & 0.57 & 1.00 & 0.42 \\
\hline \multicolumn{7}{|c|}{ Experiment 2} \\
\hline AET & 28.27 & 1.11 & 4.35 & 2.44 & 3.80 & 1.91 \\
\hline A-ET & 27.54 & 1.38 & 6.97 & 3.07 & 5.20 & 2.58 \\
\hline $\mathrm{AE}-\mathrm{T}$ & 27.33 & 1.17 & 10.15 & 3.37 & 9.98 & 2.99 \\
\hline $\mathrm{A}-\mathrm{E}-\mathrm{T}$ & 30.38 & 1.28 & 4.81 & 2.46 & 5.49 & 2.17 \\
\hline $\mathrm{A}-\mathrm{E}-\mathrm{E}-\mathrm{E}-\mathrm{T}$ & 29.32 & 1.45 & 3.51 & 1.51 & 4.82 & 1.81 \\
\hline
\end{tabular}

Note-The values in the table represent the mean number of responses corresponding to the last block of five trials of acquisition, extinction, and testing. The letters in the group names refer to the different phases (i.e., acquisition, extinction, and test), and the dash (-) denotes the moments in which a context change was performed (i.e., Experiment 1) or the extraneous stimulus was presented (i.e., Experiment 2).

als immediately prior to test. A value of .50 represents a situation in which responding during testing did not differ from responding before testing, a value lower than .50 represents suppression of responding during testing relative to the end of extinction, and a value higher than .50 represents recovery from extinction. ${ }^{3}$ An alpha level of $p<.05$ was adopted for all statistical analyses.

\section{Results and Discussion}

\section{Preliminary Analyses}

Table 2 summarizes the mean number of responses to $\mathrm{Cue} \mathrm{X}$ on the last block of five trials during acquisition, extinction, and testing. A one-way analysis of variance (ANOVA) on the mean number of responses to $\mathrm{X}$ showed that groups did not differ in (1) the last block of acquisition trials $(p>.54),(2)$ the last block of extinction trials $(p>.14)$, and (3) the block of five test trials $(p>$ .47). Despite the lack of statistical differences, the tendency toward differences in the last block of extinction trials further justified our use of FRs for analysis of the test data.

\section{Test Results}

The results of Experiment 1 are depicted in Figure 1. As can be seen, the mean FR was higher in Group A-E-T than in Groups AET and A-E-E-E-T, which apparently did not differ. These impressions were confirmed by a one-way ANOVA on mean FRs, which showed an overall effect of group $[F(2,35)=19.19, p<.001]$. Pairwise comparisons showed that the FR was higher in Group A-E-T than in both of the other groups [AET, $F(1,35)=$ $37.09, p<001 ; \mathrm{A}-\mathrm{E}-\mathrm{T}, F(1,35)=15.77, p<.001]$. Also, the FR of Group A-E-E-E-T was marginally higher than that of Group AET $[F(1,35)=3.98, p=.053]$.

The higher FR observed in Group A-E-T in comparison with Group AET in the present experiment is evidence of ABC renewal (Bouton \& Bolles, 1979). More important, when the extinction phase occurred in three different contexts (i.e., Group A-E-E-E-T), ABC renewal was attenuated, as is shown by the lower FR of Group A-E-E-E-T relative to Group A-E-T. The latter results replicate, in an associative learning preparation with humans, the results of Gunther et al. (1998), who used a conditioned lick suppression preparation with rats.

As was previously mentioned, Gunther et al.'s (1998) extension of Bouton's (1993) retrieval theory can explain these results if one assumes that in Group A-E-E-E-T, the context of testing (i.e., Context F) shared more cues with the contexts in which extinction occurred (i.e., Contexts B, C, and D) than with Context B alone. Thus, one would expect the memory of extinction to be more strongly retrieved at test by Group A-E-E-E-T, and consequently, this association should have been able to strongly interfere with retrieval of the $\mathrm{X}-\mathrm{O} 1$ association. In contrast, the signal hypothesis explains these results by assuming that, although the contextual change that occurred between acquisition and extinction allowed the par-

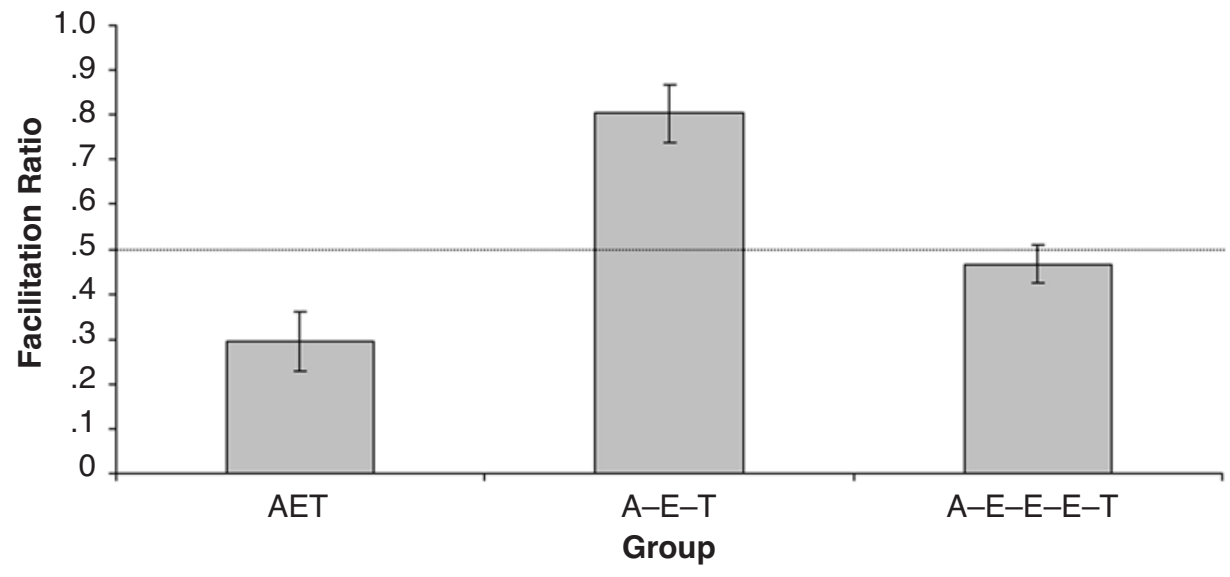

Figure 1. Results of Experiment 1. Facilitation ratio (FR) $=$ number of responses during test/ (number of responses during test + number of responses before test). The dashed horizontal line represents the value of .50 in the $F R$, in which responding during test is equal to responding prior to test. Error bars depict standard errors of the means. 
ticipants to learn that context change signaled a change in the $\mathrm{X}-\mathrm{O}$ relation (i.e., from $\mathrm{X}-\mathrm{O} 1$ to $\mathrm{X}-\mathrm{O} 3$ ) in both groups $\mathrm{A}-\mathrm{E}-\mathrm{T}$ and $\mathrm{A}-\mathrm{E}-\mathrm{E}-\mathrm{E}-\mathrm{T}$, only in Group $\mathrm{A}-\mathrm{E}-\mathrm{T}$ was this learning preserved. In Group A-E-E-E-T, the occurrence of contextual changes during extinction, being followed by no change in the $\mathrm{X}-\mathrm{O}$ relation, disconfirmed the previously learned relation between context change and the change in the meaning of the cue. Due to this, the participants in Group A-E-T could anticipate a new change in the $\mathrm{X}-\mathrm{O}$ relation following the context change that occurred just before testing (i.e., from $\mathrm{X}-\mathrm{O} 3$ to $\mathrm{X}-\mathrm{O} 1$ ), whereas the participants in Group A-E-E-E-T would have disregarded this context change as a signal for a change in the meaning of the cue. As a consequence, only the participants in Group A-E-T would have expected Cue $\mathrm{X}$ to be followed by $\mathrm{O} 1$ and would have accordingly increased responding to $\mathrm{X}$ at test.

\section{EXPERIMENT 2}

In Experiment 2, we sought to replicate the results of Experiment 1 by using, instead of a context change, the presentation of an ES, which consisted of a 30-sec presentation of a black screen (see Escobar, Arcediano, \& Miller, in press; Rudy, Rosenberg, \& Sandell, 1977, for similar manipulations in conditioning experiments with nonhuman animals). Instead of our using context changes, as in Experiment 1, in Experiment 2 we used the presentation of an ES, because the latter manipulation is less subject to alternative accounts. For example, unlike contextual manipulations, response recovery achieved by presenting an ES cannot be viewed as being due to contextual associative strength adding to residual associative strength of the cue, because the ES is not present at the time of testing. Similarly, the presentation of the ES prior to test is less likely to result in configural learning than are contextual switches (e.g., Pearce, 1987). That is, the formation of a cue-ES configuration would be expected to be weak (i.e., due to the ES and cue presentations being separated by a temporal gap), in comparison with the formation of a cue-context configuration (i.e., because the cue is presented together with the different contexts).

In Experiment 2, as in the previous experiment, all the groups received acquisition trials with $\mathrm{Cue} \mathrm{X}$ (i.e., $\mathrm{X}-\mathrm{O} 1$ ), followed by extinction trials with the same cue (i.e., $\mathrm{X}-\mathrm{O} 3$ ) and then testing of responding to Cue X. The context remained unchanged in this experiment, but the groups differed in their experiences with the ES. Group AET received no ES presentations, whereas Group A-E-T was exposed to the ES between the different phases. Group A-E-E-E-T received the ES presentations not only between phases, but also interspersed within the extinction phase. Therefore, these groups replicated those groups of Experiment 1, using the presentation of the ES, instead of the contextual changes, as the critical manipulation. To better understand any observed differences among groups, two additional groups were included in the present experiment: Group AE-T and Group A-ET. Group AE-T was presented with the ES exclusively between extinction and testing, and Group A-ET was exposed to the ES only between acquisition and extinction.

Although training and testing occurred in the same context for all the groups, the signal hypothesis suggested that the presentation of the ES between phases could make the ES effective in modulating responding to the cues at test. In the framework of the signal hypothesis, the participants might learn that, when the ES is presented between acquisition and extinction (i.e., Groups A-ET, $\mathrm{A}-\mathrm{E}-\mathrm{T}$, and $\mathrm{A}-\mathrm{E}-\mathrm{E}-\mathrm{E}-\mathrm{T})$, there is a change in the outcome that is paired with the target cue. Thus, when the ES is again presented between extinction and testing, Cue $\mathrm{X}$ would be expected to be followed by $\mathrm{O} 1$, resulting in a recovery of responding to this cue. However, in Group A-E-E-E-T, the presentation of the ES during extinction was expected to allow the participants to learn that the ES did not always signal any change in the cue-outcome relation and, thus, to produce little response recovery.

A plausible extension of Bouton's (1993) theory based on the role of the ES as a priming stimulus offers alternative predictions concerning the present experiment. In this framework, the presentation of the ES between acquisition and extinction (i.e., Groups A-ET, A-E-T, and A-E-E-E-T) could turn the ES into a priming stimulus for the subsequently trained $\mathrm{X}-\mathrm{O} 3$ association. Thus, this view predicts no recovery of responding at all in Group A-E-T, because the ES primes the $\mathrm{X}-\mathrm{O} 3$ association and the $\mathrm{X}-\mathrm{O} 3$ association is already active during the extinction phase, due to recency of its training. If anything, the ES should more strongly prime the $\mathrm{X}-\mathrm{O} 3$ association, increasing the interference caused by this association with retrieval of the $\mathrm{X}-\mathrm{O} 1$ association, and thus, reduce responding to $\mathrm{X}$ (provided that the response was not subject to a floor effect). In Group A-E-E-E-T, due to the larger number of presentations of the ES, each followed by training of the $\mathrm{X}-\mathrm{O} 3$ association, priming of the $\mathrm{X}-\mathrm{O} 3$ association should be even stronger and, hence, responding weaker. Finally, in Group AE-T, the ES should produce no effect on responding to $X$ at testing, because in this group the ES is presented between extinction and testing for the first time and, thus, does not prime any memory.

In sum, the signal hypothesis predicts a recovery of responding in Group A-E-T, as well as an attenuated recovery of responding in Group A-E-E-E-T. In contrast, a plausible extension of Bouton's (1993) retrieval theory in which the ES is regarded as a priming stimulus predicts no recovery in any group, including Group A-E-T.

\section{Method}

\section{Participants and Apparatus}

The apparatus was identical to that in Experiment 1. The participants were 76 students ( 34 men and 42 women, with a mean age of 19.0 years $[S E M=0.32]$ ) from an introductory psychology course at SUNY-Binghamton, who participated in this experiment in partial fulfillment of a course requirement. The participants were assigned to one of five groups, resulting in $15,15,14,15$, and 17 participants in Groups AET, A-ET, AE-T, A-E-T, and A-E-E-E-T, respectively. None of the participants had served in Experiment 1. 
Table 3

Design of Experiment 2

\begin{tabular}{lcrc}
\hline \multicolumn{1}{c}{ Group } & Acquisition & Extinction & Test \\
\hline AET & $15 \mathrm{X} \rightarrow \mathrm{O} 1 / 15 \mathrm{Y} \rightarrow \mathrm{O} 2-15 \mathrm{X} \rightarrow \mathrm{O} 3$ & $-5 \mathrm{X} \rightarrow \mathrm{O} 3$ \\
$\mathrm{~A}-\mathrm{ET}$ & $15 \mathrm{X} \rightarrow \mathrm{O} 1 / 15 \mathrm{Y} \rightarrow \mathrm{O} 2$ ES $15 \mathrm{X} \rightarrow \mathrm{O} 3$ & $-5 \mathrm{X} \rightarrow \mathrm{O} 3$ \\
$\mathrm{AE}-\mathrm{T}$ & $15 \mathrm{X} \rightarrow \mathrm{O} 1 / 15 \mathrm{Y} \rightarrow \mathrm{O} 2-15 \mathrm{X} \rightarrow \mathrm{O} 3$ & ES $5 \mathrm{X} \rightarrow \mathrm{O} 3$ \\
$\mathrm{~A}-\mathrm{E}-\mathrm{T}$ & $15 \mathrm{X} \rightarrow \mathrm{O} 1 / 15 \mathrm{Y} \rightarrow \mathrm{O} 2$ ES $15 \mathrm{X} \rightarrow \mathrm{O} 3$ & ES $5 \mathrm{X} \rightarrow \mathrm{O} 3$ \\
$\mathrm{~A}-\mathrm{E}-\mathrm{E}-\mathrm{E}-\mathrm{T}$ & $15 \mathrm{X} \rightarrow \mathrm{O} 1 / 15 \mathrm{Y} \rightarrow \mathrm{O} 2$ ES $5 \mathrm{X} \rightarrow \mathrm{O} 3$, ES ES $5 \mathrm{X} \rightarrow \mathrm{O} 3$ \\
& \multicolumn{4}{c}{$5 \rightarrow \mathrm{O}$, ES } \\
& $5 \mathrm{X} \rightarrow \mathrm{O} 3$ \\
\hline
\end{tabular}

Note-The letters in the group names refer to the different phases (i.e., acquisition, extinction, and test), and the dash (-) denotes the moments in which the extraneous stimulus (ES) was presented. X was the target cue, and $\mathrm{Y}$ was introduced to prevent strong stimulus generalization. Presentations of $\mathrm{X}$ were followed by Outcome 1 (O1) during the acquisition phase and by Outcome 3 (O3) during the extinction phase. Presentations of $Y$ were always followed by Outcome $2(\mathrm{O} 2)$. Trial types separated by a slash were interspersed. The numbers denote the number of presentations of each trial type in each phase.

\section{Design and Procedure}

Unless otherwise stated, all of the procedural details of this experiment were identical to those in Experiment 1. Table 3 summarizes the design for this experiment. All the groups were exposed to identical treatment with the cues in the different phases. As in Experiment 1 , during the acquisition phase, all the groups were given 15 presentations of Cue $\mathrm{X}$ always followed by $\mathrm{O} 1$ (i.e., $\mathrm{X}-\mathrm{O} 1$ ), interspersed with 15 presentations of Cue $\mathrm{Y}$ always followed by $\mathrm{O} 2$ (i.e., Y-O2). During the extinction phase, all the groups were given 15 presentations of Cue $\mathrm{X}$ always followed by $\mathrm{O} 3$ (i.e., $\mathrm{X}-\mathrm{O} 3$ ). Finally, all the groups received 5 presentations of $\mathrm{X}$ followed by $\mathrm{O} 3$ during the test phase.

In this experiment, no contextual change took place (i.e., training and testing occurred always in the same context: Bow Town). The critical manipulation in this experiment was the presentation, at specific moments during treatment of an ES, which consisted of a 30 -sec presentation of a black screen with the following text in yellow:

You now have a chance to have a rest!!!

When this black screen disappears, you will be allowed to continue your mission as you have been doing up to now.

Importantly, the participants received no prior instruction concerning the presentation of this ES. The different groups differed in the number of ES presentations, as well as in the moment(s) during treatment in which the ES was presented. Group AET was never exposed to the ES. Groups A-ET and AE-T were given one ES presentation, either between acquisition and extinction (Group A-ET) or between extinction and test (Group AE-T). Group A-E-T received two ES presentations, one between the acquisition and the extinction phases, and the other between extinction and test. Finally, Group A-E-E-E-T received, as did Group A-E-T, one presentation of the ES between acquisition and extinction and one between extinction and test and, in addition, was exposed twice to the ES during extinction. Specifically, Group A-E-E-E-T was given one ES presentation after the first and second blocks of five $\mathrm{X}-\mathrm{O} 3$ trials of extinction.

\section{Preanalysis Treatment of the Data: Data Selection Criteria}

The same data selection criteria as those in Experiment 1 were used in the present experiment. No participant was eliminated for failing to pass the discrimination criterion, but the data from 3 participants (i.e., 1 each from groups AET, A-ET, and AE-T) were eliminated for failing to pass the extinction criterion.

\section{Results and Discussion \\ Preliminary Analyses}

Table 2 summarizes the mean number of responses to Cue $\mathrm{X}$ on the last block of five trials during acquisition, extinction, and testing. A one-way ANOVA on the mean number of responses to $\mathrm{X}$ showed that the groups did not differ in (1) the last block of acquisition trials $(p>.44)$, (2) the last block of extinction trials $(p>.39)$, and (3) the block of five test trials $(p>.40)$. Nevertheless, as in Experiment 1 , the variation in performance at the end of extinction encouraged the use of an FR in analyzing the test scores.

\section{Test Results}

Figure 2 depicts the main results of Experiment 2. As can be seen, the mean FR was higher in Group A-E-T than in the rest of the groups, which apparently did not differ among themselves. This impression was supported by a one-way ANOVA on the mean FR, which showed an overall effect of group $[F(4,68)=3.70, p<.01]$. Pairwise comparisons showed that the FR was similar in Groups AET, AE-T, AE-T, and A-E-E-E-T (all $p$ s > .26) and, more important, that the FR was lower in these groups than in Group A-E-T [all $F \mathrm{~s}(1,68)>5.57, p \mathrm{~s}<.05]$.

Thus, the results of groups AET, A-E-T, and A-EE-E-T of this experiment replicated those in Experiment 1, despite the use of the ES in place of a shift in spatial context. The higher FR in Group A-E-T than in Group AET in the present experiment shows that the response recovery observed in Experiment 1 is not specific to changes in spatial context but obtains whenever a disruptive manipulation is performed between the different phases. Moreover, presenting the ES twice during the extinction phase in Group A-E-E-E-T was enough to attenuate the response recovery observed during testing in Group A-E-T. Thus, as in Experiment 1, the effectiveness of the critical manipulation (i.e., the context changes in Experiment 1 and the presentation of the ES in the present experiment) decreased when that manipulation also occurred during the extinction phase. In addition, these results showed that the recovery of responding was not observed when the ES was presented for the first time before testing (i.e., Group AE-T) or when the ES presentations were given between acquisition and extinction, but not before testing (i.e., Group A-ET).

These findings cannot be explained by the proposed extension of Bouton's (1993) theory. As was previously mentioned, this extension of the theory predicts that the presentation of the ES turns the ES into a priming stimulus for the subsequently trained association. In this experiment, because the ES was presented between acquisition and extinction to Group A-E-T, the ES should have become a priming stimulus for the $\mathrm{X}-\mathrm{O} 3$ association. Thus, the presentation of the ES before testing should have retrieved the memory of the $\mathrm{X}-\mathrm{O} 3$ (instead of the $\mathrm{X}-\mathrm{O} 1$ ) association during testing, resulting in no 


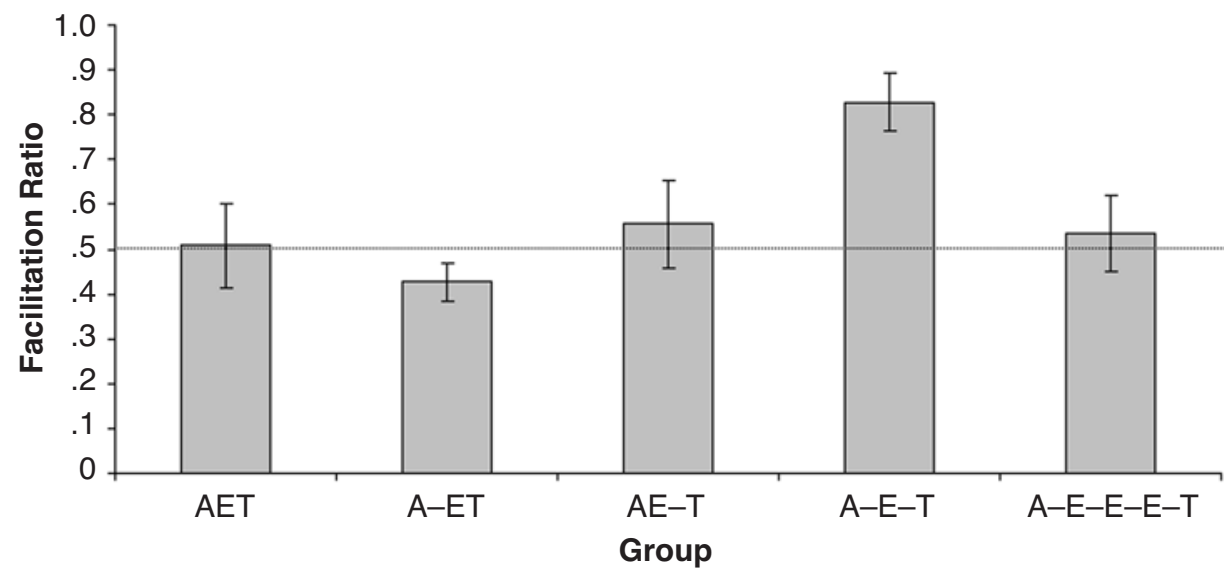

Figure 2. Results of Experiment 2. Facilitation ratio (FR) $=$ number of responses during test/(number of responses during test + number of responses before test). The dashed horizontal line represents the value of .50 in the FR, in which responding during test is equal to responding prior to test. Error bars depict standard errors of the means.

recovery of responding to $\mathrm{X}$ during testing. Of course, we must acknowledge that Groups A-E-T and A-E$\mathrm{E}-\mathrm{E}-\mathrm{T}$ were not equated in number of ES presentations followed by extinction, so it is still possible that ES presentations primed the extinction phase for Group A-EE-E-T, but not for Group A-E-T.

Alternatively, Bouton's (1993) theory could view each ES presentation as producing a change in the temporal context, in that it did add an interval not experienced by the participants lacking the ES presentation. In this case, this theory could explain the recovery of responding observed in Group A-E-T (i.e., presenting the ES before testing consisted of testing $\mathrm{X}$ in a temporal context different from that of extinction). Also, performing extinction training in different temporal contexts (i.e., Group A-E-E-E-T) could have enhanced retrieval of the $\mathrm{X}-\mathrm{O} 3$ association at test and, hence, attenuate response recovery. However, this account of Experiment 2 fails to explain why spontaneous recovery of responding was not observed in Group AE-T. If the mechanism responsible for response recovery in Group A-E-T is the impaired retrieval of the $\mathrm{X}-\mathrm{O} 3$ association at test, due to performing extinction, training, and testing in different temporal contexts, recovery of responding should be expected, not only in Group A-E-T, but also in Group AE-T. The observation of response recovery in Group A-E-T, but not in Group AE-T, suggests that the former group learned something important on the basis of the ES presentation that occurred between acquisition and extinction, something that Group AE-T could not have learned.

The signal hypothesis, however, provides a complete account for the present results. In this view, presentation of the ES between acquisition and extinction (i.e., in Groups A-ET, A-E-T, and A-E-E-E-T) allowed the ES to become a signal for a change in the $\mathrm{X}-\mathrm{O}$ relationship (from $\mathrm{X}-\mathrm{O} 1$ in acquisition to $\mathrm{X}-\mathrm{O} 3$ in extinction). Among these groups, only the participants in Group A-E-T could expect a new change in the $\mathrm{X}-\mathrm{O}$ relation during testing. This expectation would not exist in Group A-ET, because the ES was not presented between extinction and test, whereas in Group A-E-E-E-T this expectation would have been impaired by the two presentations of the ES during the extinction phase (i.e., presentations of the ES followed by no change in the $\mathrm{X}-\mathrm{O}$ relation). Moreover, although the ES was presented to Group AE-T before testing, the participants in this group had never before experienced the ES; thus, there was no reason why they should have expected any change in the meaning of Cue $\mathrm{X}$ on the basis of the ES presentation.

\section{EXPERIMENT 3}

In the prior experiments, we investigated $\mathrm{ABC}$ renewal of responding following extinction (i.e., condition A-E-T) and how this kind of renewal can be attenuated by performing contextual changes (Experiment 1) or presenting an ES (Experiment 2) during extinction treatment (i.e., condition A-E-E-E-T). However, as was previously mentioned, both Bouton's (1993) retrieval failure theory and the signal hypothesis can explain the results of Experiments 1 and 2. Specifically, Bouton's (1993) theory could assume that performing extinction in several contexts, either physical (Experiment 1) or temporal (Experiment 2), facilitated retrieval of the inhibitory association at test and, thus, impaired response recovery. Alternatively, the signal hypothesis could assume that, although the participants in both Groups A-E-T and A-EE-E-T first learned to predict a change in the cue-outcome relation on the basis of the manipulation (i.e., the context switch or the ES presentation) performed between the acquisition and the extinction phases, during extinction the participants in Group A-E-E-E-T also learned that these contextual changes or ES presentations no longer predicted a change in the meaning of the cue. Thus, when the participants in Group A-E-E-E-T were exposed to another context change or ES presentation prior to testing, 
these participants did not expect the cue to newly predict the outcome, as the participants in Group A-E-T did.

Therefore, although interesting, the results of Experiments 1 and 2 are not conclusive regarding which one of the two candidate accounts - namely, Bouton's (1993) theory or our signal hypothesis - better explains the response recovery and the attenuation of response recovery observed in Groups A-E-T and A-E-E-E-T, respectively. Thus, Experiment 3 was performed in order to contrast the previously suggested extension of Bouton's (1993) theory and the signal hypothesis. To achieve this, in Experiment 3 we used a discrimination reversal design (e.g., Chiszar \& Spear, 1965; see also Vila, Romero, \& Rosas, 2002, for a study with humans), in which the target cues, $\mathrm{X}$ and $\mathrm{Y}$, were trained with either $\mathrm{O} 1$ or $\mathrm{O} 3$ in different phases. Also, instead of a three-phase design (i.e., acquisition, extinction, and test), as in Experiments 1 and 2, in Experiment 3 a four-phase design was used (i.e., acquisition, extinction, reacquisition, and test). Specifically, during acquisition, $\mathrm{X}$ and $\mathrm{Y}$ were paired with $\mathrm{O} 1$ and O3, respectively. During extinction of $\mathrm{X}$, these relations were reversed: $\mathrm{X}$ was paired with $\mathrm{O} 3$ and $\mathrm{Y}$ with O1. During reacquisition, $\mathrm{X}$ and $\mathrm{Y}$ were again paired with their original outcomes: $\mathrm{O} 1$ and $\mathrm{O} 3$, respectively. During testing, the participants within each group were tested on either X or Y, with $\mathrm{O} 3$ as the outcome (see Table 4).

As in Experiment 2, the critical manipulation in this experiment was the number of presentations of the ES, as well as the moment(s) in which the ES was presented during treatment. Group AERT (the letters in the name represent the different phases of the experiment with respect to the treatment received by Cue X: acquisition [A], extinction [E], reacquisition [R] , and test [T]) was never exposed to the ES. Group AER-T received the ES only between reacquisition and test, whereas Group A-E-RT was given ES presentations between acquisition and extinction and between extinction and reacquisition. Finally, Group A-E-R-T was given one ES presentation between each of the different phases (i.e., acquisition and extinction, extinction and reacquisition, and reacquisition and test).

The use of a four-phase design in this experiment was important because, as can be seen in Table 4, the associations trained just prior to testing were also the associations that were learned in the first place. Therefore, according to the suggested extension of Bouton's (1993, 1997; see also Bouton \& Nelson, 1998) theory, in which the ES is re- garded as a priming stimulus for the inhibitory or secondtrained association, the ES presentations given before testing in Groups AER-T and A-E-R-T should be irrelevant to responding to the cues. In Group AER-T, the ES cannot prime any specific association before testing, due to its being presented for the first time, and in Group A-E-R-T, the ES should equally serve as a priming stimulus for all the different associations. Due to the presentation of the ES before the extinction phase, the ES could become a priming stimulus for the $\mathrm{X}-\mathrm{O} 3$ and $\mathrm{Y}-\mathrm{O} 1$ associations, whereas due to the presentation of the ES before reacquisition, the ES could become a priming stimulus for the $\mathrm{X}-\mathrm{O} 1$ and $\mathrm{Y}-\mathrm{O} 3$ associations.

One might propose that presenting the ES just prior to testing would have a (nonassociative) disruptive influence on retrieval of either the inhibitory association (Bouton, 1993) or the second-learned association (Bouton, 1997). Although this alternative view of the role of the ES presentation could explain the response recovery to Cue $\mathrm{X}$ during testing observed in Group A-E-T (Experiment 2), it fails to explain the lack of recovery in both Group AE-T and Group A-E-E-E-T (Experiment 2). However, it would be worthwhile to entertain the predictions of this view in the present experiment. On the one hand, if the ES disrupted retrieval of inhibitory $\mathrm{X}-\mathrm{O} 3$ and $\mathrm{Y}-\mathrm{O} 3$ associations (Bouton, 1993), then (1) given that learning of all associations was asymptotic, responding to both $\mathrm{X}$ and $\mathrm{Y}$ should be similarly strong, or (2) responding to $X$ should be stronger than responding to $\mathrm{Y}$, because $\mathrm{X}$ received more pairings with $\mathrm{O} 1$ than did $\mathrm{Y}$. On the other hand, if the ES disrupted retrieval of the second-learned $\mathrm{X}-\mathrm{O} 3$ and Y-O1 associations (Bouton, 1997), stronger responding to $X$ than to $Y$ should be observed. In any case, neither the view that inhibitory associations are context dependent (Bouton, 1993) nor the view that second-learned associations are context dependent (Bouton, 1997) would predict responding to $\mathrm{Y}$ to be stronger than responding to $\mathrm{X}$. Moreover, because the previous history of the ES is irrelevant within this framework (i.e., the mere presentation of the ES prior to testing is all that is needed in order to disrupt retrieval), these predictions should also apply to Groups AER-T and A-E-R-T.

The predictions of the signal hypothesis are straightforward. On the basis of the experience with the ES between acquisition and extinction and between extinction and reacquisition, Groups A-E-RT and A-E-R-T will learn that each ES presentation is followed by a reversal

Table 4

Design of Experiment 3

\begin{tabular}{lccccccc}
\hline Group & Acquisition & & Extinction & Reacquisition & Test \\
\hline AERT & $10 \mathrm{X} \rightarrow \mathrm{O} 1 / 10 \mathrm{Y} \rightarrow \mathrm{O} 3$ & - & $10 \mathrm{X} \rightarrow \mathrm{O} 3 / 10 \mathrm{Y} \rightarrow \mathrm{O} 1$ & - & $10 \mathrm{X} \rightarrow \mathrm{O} 1 / 10 \mathrm{Y} \rightarrow \mathrm{O} 3$ & - & $1 \mathrm{X} \rightarrow \mathrm{O} 3$ or $1 \mathrm{Y} \rightarrow \mathrm{O} 3$ \\
$\mathrm{AER}-\mathrm{T}$ & $10 \mathrm{X} \rightarrow \mathrm{O} 1 / 10 \mathrm{Y} \rightarrow \mathrm{O} 3$ & - & $10 \mathrm{X} \rightarrow \mathrm{O} 3 / 10 \mathrm{Y} \rightarrow \mathrm{O} 1$ & - & $10 \mathrm{X} \rightarrow \mathrm{O} 1 / 10 \mathrm{Y} \rightarrow \mathrm{O} 3$ & ES & $1 \mathrm{X} \rightarrow \mathrm{O} 3$ or $1 \mathrm{Y} \rightarrow \mathrm{O} 3$ \\
$\mathrm{~A}-\mathrm{E}-\mathrm{RT}$ & $10 \mathrm{X} \rightarrow \mathrm{O} 1 / 10 \mathrm{Y} \rightarrow \mathrm{O} 3$ & ES & $10 \mathrm{X} \rightarrow \mathrm{O} 3 / 10 \mathrm{Y} \rightarrow \mathrm{O} 1$ & ES & $10 \mathrm{X} \rightarrow \mathrm{O} 1 / 10 \mathrm{Y} \rightarrow \mathrm{O} 3$ & - & $1 \mathrm{X} \rightarrow \mathrm{O} 3$ or $1 \mathrm{Y} \rightarrow \mathrm{O} 3$ \\
$\mathrm{~A}-\mathrm{E}-\mathrm{R}-\mathrm{T}$ & $10 \mathrm{X} \rightarrow \mathrm{O} 1 / 10 \mathrm{Y} \rightarrow \mathrm{O} 3$ & ES & $10 \mathrm{X} \rightarrow \mathrm{O} 3 / 10 \mathrm{Y} \rightarrow \mathrm{O} 1$ & ES & $10 \mathrm{X} \rightarrow \mathrm{O} 1 / 10 \mathrm{Y} \rightarrow \mathrm{O} 3$ & ES & $1 \mathrm{X} \rightarrow \mathrm{O} 3$ or $1 \mathrm{Y} \rightarrow \mathrm{O} 3$ \\
\hline
\end{tabular}

Note-The letters in the group names refer to the different phases (i.e., acquisition, extinction, reacquisition, and test), and the dash $(-)$ denotes the moments in which the extraneous stimulus (ES) was presented. X and Y were the target cues. Presentations of $X$ and $\mathrm{Y}$ were followed by either Outcome $1(\mathrm{O} 1)$ or Outcome 3 (O3) during the different phases. Trial types separated by a slash were interspersed. The numbers denote the number of presentations of each trial type in each phase. 
of the meaning of the cues. In contrast, Groups AERT and AER-T lack experience with the ES during these phases; thus, the ES cannot become a signal for a change in the cue-outcome relation. Therefore, the presentation of the ES between reacquisition and testing would be expected to have a different consequence in groups AER-T and A-E-R-T. In Group AER-T, the presentation of the ES should have no effect. If anything, this presentation should produce a generalization decrement effect (Pavlov, 1927; Pearce, 1987), which would be more strongly reflected in responding to Cue $\mathrm{X}$ than in responding to Cue $\mathrm{Y}$, due to their different baselines of responding during reacquisition (i.e., stronger responding to $\mathrm{X}$ than to $\mathrm{Y}$, due to the training of the $\mathrm{X}-\mathrm{O} 1$ and $\mathrm{Y}-\mathrm{O} 3$ associations during this phase). However, in Group A-E-R-T, the presentation of the ES before testing should produce an expectation of a reversal from acquisition in the meanings of the cues. Because Cues $\mathrm{X}$ and $\mathrm{Y}$ were paired with $\mathrm{O} 1$ and $\mathrm{O} 3$ during reacquisition, the participants of this group should expect $\mathrm{X}$ to be followed by $\mathrm{O} 3$ and $\mathrm{Y}$ by $\mathrm{O} 1$ during testing. In summary, according to the signal hypothesis, responding to $\mathrm{Y}$ should be stronger than responding to $\mathrm{X}$ only in Group A-E-R-T.

Method
Participants and Apparatus
The apparatus was identical to that in Experiments 1 and 2. The
participants were 102 students ( 39 men and 63 women, with a mean
age of 19.1 years [SEM $=0.11]$ ) from an introductory psychology
course at SUNY-Binghamton, who participated in this experiment in
partial fulfillment of a course requirement. The participants were as-
signed to one of four groups, resulting in $29,23,25$, and 25 partici-
pants in each of groups AERT, AER-T, A-E-RT, and A-E-R-T, re-
spectively. None of the participants had served in Experiment 1 or 2.

\section{Design and Procedure}

Unless otherwise mentioned, all the procedural details in this experiment were identical to those in Experiments 1 and 2. Table 4 summarizes the design for this experiment. All the groups were exposed to identical treatments with the cues in the different phases. During the acquisition ( of $\mathrm{X}$ ) phase, all the groups were given 10 presentations of Cue $\mathrm{X}$ followed by $\mathrm{O} 1$ (i.e., $\mathrm{X}-\mathrm{O} 1$ ), interspersed with 10 presentations of Cue $\mathrm{Y}$ followed by $\mathrm{O} 3$ (i.e., $\mathrm{Y}-\mathrm{O} 3$ ). In the extinction (of $\mathrm{X}$ ) phase, these contingencies were reversed: All the groups were given 10 presentations of Cue $\mathrm{X}$ followed by $\mathrm{O} 3$ (i.e., $\mathrm{X}-\mathrm{O} 3$ ), interspersed with 10 presentations of Cue $\mathrm{Y}$ followed by $\mathrm{O} 1$ (i.e., $\mathrm{Y}-\mathrm{O} 1$ ). The contingencies were again reversed in the reacquisition (of $\mathrm{X}$ ) phase, resulting in a training identical to that in the acquisition phase (i.e., 10 presentations of $\mathrm{X}-\mathrm{O} 1$ interspersed with 10 presentations of $\mathrm{Y}-\mathrm{O} 3$ ).

In each phase, $\mathrm{X}-\mathrm{O} 1$ and $\mathrm{Y}-\mathrm{O} 3$ trials were presented according to the same pseudorandom sequence as that used for the $\mathrm{X}-\mathrm{O} 1$ and $\mathrm{Y}-\mathrm{O} 2$ trials in Experiments 1 and 2, with the only exception being that, in this experiment, 10 presentations of each trial type were given. (In this experiment, we did not include trials with $\mathrm{O} 2$, in order to avoid their interfering with learning the reversal of the meaning of Cues X and Y.) During testing, approximately half of the participants in each group were tested on $\mathrm{X}$ (i.e., one $\mathrm{X}-\mathrm{O} 3$ trial), and the other half of the participants were tested on Y (i.e., one Y-O3 trial). This assignment of participants in each group to testing with either $\mathrm{X}$ or $\mathrm{Y}$ resulted in the following distribution of the sample: Group AERT, $n_{\mathrm{X}}=17, n_{\mathrm{Y}}=12$; Group AER-T, $n_{\mathrm{X}}=12, n_{\mathrm{Y}}=11$; Group
A-E-RT, $n_{\mathrm{X}}=13, n_{\mathrm{Y}}=12$; and Group A-E-R-T, $n_{\mathrm{X}}=14, n_{\mathrm{Y}}=$ 11. For the reasons described below, there was only one test trial.

In the present experiment, the critical manipulation was (as in Experiment 2) the number of presentations of the ES, as well as the moment(s) in which the ES was presented during training. The ES presented in this experiment was identical to the ES used in Experiment 2. Group AERT was never exposed to the ES. Group AER-T was given one presentation of the ES between the reacquisition and the test phases. Group A-E-RT received ES exposures between acquisition and extinction and between extinction and reacquisition, but not before testing. Finally, in Group A-E-R-T, all the phases were separated by the presentation of the ES.

\section{Preanalysis Treatment of the Data}

Data selection criterion. The design of the present experiment did not allow the use of the extinction criterion that was used in Experiments 1 and 2. Because in this experiment both Cues $\mathrm{X}$ and $\mathrm{Y}$ were target cues, the extinction criterion might have been applied to both cues. However, extinction of X took place in the second phase of the experiment, whereas extinction of $Y$ was given in the third phase of the experiment. This asymmetrical training order of the cues would have resulted in substantial differences in sensitivity to the extinction criterion for the cues. Moreover, $\mathrm{X}$ and $\mathrm{Y}$ initially received training with the appetitive outcome $(\mathrm{O} 1)$ and the neutral outcome (O3), respectively. Nevertheless, the discrimination criterion could be used as a criterion. In addition, because in the present experiment both Cues $\mathrm{X}$ and $\mathrm{Y}$ were paired with either $\mathrm{O} 1$ or $\mathrm{O} 3$ in the different phases, the discrimination criterion could be applied in the acquisition, extinction, and reacquisition phases. Thus, the following criteria were applied in order to accept the data in the present experiment: (1) In acquisition and reacquisition phases, the number of responses given during the last block of five trials with $\mathrm{X}-\mathrm{O} 1 \mathrm{had}$ to be higher than the number of responses given during the last block of five trials with $\mathrm{Y}-\mathrm{O} 3$, and (2) in the extinction phase, the number of responses given during the last block of five trials with $\mathrm{Y}-\mathrm{O} 1$ had to be higher than the number of responses given during the last block of five trials with $\mathrm{X}-\mathrm{O} 3$. As a result of the application of these criteria, data from 3 participants (i.e., 2 from Group AERT and 1 from Group AER-T) were eliminated from the analyses.

Analyses of mean number of responses. As was previously mentioned, in this experiment, our interest was the study of the influence of the ES presentations on discrimination reversal learning. Thus, responding to Cues $\mathrm{X}$ and $\mathrm{Y}$ needs to be compared in order to determine whether the ES presentation produced, in each group, an expectation of a reversal of the meaning of the cues. However, due to the different baselines of responding to Cues $\mathrm{X}$ and $\mathrm{Y}$ at the end of the reacquisition phase (i.e., responding to $X$ was expected to be stronger than responding to $\mathrm{Y}$, because in reacquisition $\mathrm{X}$ was rewarded and $\mathrm{Y}$ was not), the FRs of Cues $\mathrm{X}$ and $\mathrm{Y}$ could not be directly compared. Responding to $\mathrm{X}$ was subject to a ceiling effect (i.e., responding to $X$ could decrease, but it could hardly increase), whereas responding to $\mathrm{Y}$ was subject to a floor effect (i.e., responding to $\mathrm{Y}$ could increase, but it could hardly decrease). Thus, contrary to the analyses in Experiments 1 and 2, calculation of an FR would not have been appropriate in Experiment 3. Because the comparison between responding to $\mathrm{X}$ and $\mathrm{Y}$ in each group was critical in this experiment, we analyzed the mean number of responses to Cues X and Y.

Also, only one test trial could be used in the present experiment. If both $\mathrm{X}$ and $\mathrm{Y}$ were paired with $\mathrm{O} 3$ during five test trials (as in Experiments 1 and 2), the presentation of $\mathrm{X}-\mathrm{O} 3$ and $\mathrm{Y}-\mathrm{O} 3$ trials during testing would have produced opposite effects on responding to $\mathrm{X}$ and $\mathrm{Y}$, relative to the previous type of trials presented during the reacquisition phase (i.e., $\mathrm{X}-\mathrm{O} 1$ and $\mathrm{Y}-\mathrm{O} 3$ ). Specifically, the presentation of the ES before testing in Group A-E-R-T was expected 
to be a signal for a change in the meaning of the cues. Because Cue $\mathrm{X}$ was paired with $\mathrm{O} 1$ during reacquisition, the presentation of the ES was expected to signal the presentation of $\mathrm{X}-\mathrm{O} 3$ trials. Since $\mathrm{X}-\mathrm{O} 3$ trials would be presented during testing, the presentation of $\mathrm{X}-\mathrm{O} 3$ trials would confirm the previous expectation raised by the immediately prior presentation of the ES. By contrast, the presentation of the ES just prior to testing was expected to signal the presentation of $\mathrm{Y}-\mathrm{O} 1$ trials during test. Because $\mathrm{Y}-\mathrm{O} 3$ trials (instead of $\mathrm{Y}-\mathrm{O} 1$ trials) would be presented, the prior expectation raised by the ES would be disconfirmed by the first trial. This disconfirmation of previous expectations likely would have decreased responding to $\mathrm{Y}$ on the subsequent test trials of Group A-E-R-T, therefore reducing the sensitivity of our present design for detecting any influence of the presentation of the ES in responding to $\mathrm{Y}$ at test. Therefore, in the analyses of the test trial data, we analyzed responses only in the last trial of reacquisition (hereafter referred to as the $\mathrm{R}$ trial) and the single test trial (hereafter referred to as the $\mathrm{T}$ trial) for each group.

\section{Results and Discussion}

\section{Preliminary Analyses}

Table 5 summarizes the mean number of responses to Cues $\mathrm{X}$ and $\mathrm{Y}$ on the last block of five trials during the acquisition, extinction, and reacquisition phases of Experiment 3 . A 4 (group) $\times 2$ (cue) $\times 3$ (phase) ANOVA on the mean number of responses showed main effects of cue $[F(1,95)=657.72, p<.01]$ and phase $[F(2,190)=12.19$, $p<.01]$, as well as cue $\times$ block $[F(2,190)=1,043.28$, $p<.01]$ and group $\times$ cue $\times$ phase $[F(6,190)=2.28, p<$ .05] interactions.

In order to explore this three-way interaction, separate ANOVAs were performed on each block of five trials. A 4 (group) $\times 2$ (cue) ANOVA on the mean number of responses in the last five-trial block of acquisition showed only a main effect of cue $[F(1,95)=879.36, p<.01]$. The main effect of group and the group $\times$ cue interaction were not significant (all $p s>.81$ ). An identical ANOVA on the mean number of responses in the last five-trial block of extinction showed a main effect of cue $[F(1,95)=$ $1190.47, p<.01]$ and a group $\times$ cue interaction $[F(3,95)=2.94, p<.05]$. The main effect of group was not significant $(p>.53)$. Thus, at the end of the extinction phase, responding to $\mathrm{X}$ and to $\mathrm{Y}$ differed among

Table 5

Mean Number of Responses to $X$ and $Y$ in Experiment 3

\begin{tabular}{|c|c|c|c|c|c|c|c|}
\hline \multirow[b]{2}{*}{ Group } & \multirow[b]{2}{*}{ Cue } & \multicolumn{2}{|c|}{ Acquisition } & \multicolumn{2}{|c|}{ Extinction } & \multicolumn{2}{|c|}{ Reacquisition } \\
\hline & & $M$ & SEM & $M$ & SEM & $M$ & $S E M$ \\
\hline \multirow[t]{2}{*}{ AERT } & $X$ & 25.68 & 0.87 & 3.82 & 1.59 & 27.61 & 1.46 \\
\hline & $\mathrm{Y}$ & 1.85 & 0.99 & 27.00 & 1.18 & 4.54 & 1.59 \\
\hline \multirow[t]{2}{*}{ AER-T } & $\mathrm{X}$ & 24.68 & 1.41 & 1.50 & 0.65 & 26.97 & 1.76 \\
\hline & $\mathrm{Y}$ & 0.84 & 0.43 & 26.33 & 1.47 & 1.60 & 0.80 \\
\hline \multirow[t]{2}{*}{ A-E-RT } & $X$ & 25.35 & 1.79 & 1.42 & 0.86 & 30.62 & 1.44 \\
\hline & $\mathrm{Y}$ & 2.47 & 1.38 & 29.94 & 1.42 & 1.12 & 0.83 \\
\hline \multirow[t]{2}{*}{$\mathrm{A}-\mathrm{E}-\mathrm{R}-\mathrm{T}$} & $\mathrm{X}$ & 25.42 & 1.28 & 0.71 & 0.29 & 28.80 & 1.20 \\
\hline & $\mathrm{Y}$ & 1.52 & 0.75 & 28.66 & 1.17 & 0.95 & 0.58 \\
\hline
\end{tabular}

Note-The values in the table represent the mean number of responses to Cues $\mathrm{X}$ and $\mathrm{Y}$ corresponding to the last block of five trials of each phase. The letters in the group names refer to the different phases (i.e., acquisition, extinction, reacquisition, and test), and the dash (-) denotes the moments in which the extraneous stimulus was presented. groups, probably due to differences among the groups in the ES presentations between acquisition and extinction. More important for our purposes, an identical ANOVA on the mean number of responses in the last five-trial block of reacquisition also showed a main effect of cue $[F(1,95)=921.53, p<.01]$, as well as a group $\times$ cue interaction $[F(1,95)=2.74, p<.05]$. The main effect of group was not significant $(p>.50)$. In order to further study the source of this interaction, due to its relevance for our analyses on the test results, separate analyses were performed on the number of responses to $\mathrm{X}$ and $\mathrm{Y}$. A oneway ANOVA on the mean number of responses to $X$ in the last block of trials of reacquisition showed no difference among groups $(p>.32)$. Therefore, responding to $\mathrm{X}$ in the last block of trials of reacquisition did not appreciably affect the results of testing. A one-way ANOVA on the mean number of responses to $\mathrm{Y}$ in the last block of trials of reacquisition yielded a marginal difference among groups $[F(3,95)=2.62, p=.055]$. Post hoc comparisons using Bonferroni's correction showed that responding to $\mathrm{Y}$ in the last block of trials of reacquisition did not appreciably differ among groups (all $p \mathrm{~s}>.10$ ).

\section{Test Results}

The mean number of responses to Cues $\mathrm{X}$ and $\mathrm{Y}$ in the $\mathrm{R}$ and the $\mathrm{T}$ trials for each group is represented in the different panels of Figure 3. A 4 (group) $\times 2$ (cue: X vs. Y) $\times 2$ (trial: R vs. T) ANOVA on the mean number of responses showed main effects of group $[F(3,91)=9.23$, $p<.001]$, cue $[F(1,91)=297.14, p<.001]$, and trial $[F(1,91)=27.51, p<.001]$. This ANOVA also detected group $\times$ cue $[F(3,91)=18.06, p<.001]$, group $\times$ trial $[F(3,91)=10.83, p<.001]$, cue $\times$ trial $[F(1,91)=$ $78.48, p<.001]$, and group $\times$ cue $\times$ trial $[F(3,91)=$ $44.42, p<.001]$ interactions. In order to further study the source of these different interactions, planned comparisons were performed on responding to $\mathrm{X}$ and $\mathrm{Y}$ in the different trials for each individual group.

Panel A of Figure 3 depicts responding to $\mathrm{X}$ and $\mathrm{Y}$ on the $R$ and the $T$ trials in Group AERT. As can be seen in panel $\mathrm{A}$, responding to $\mathrm{X}$ was stronger than responding to $\mathrm{Y}$ on the $\mathrm{T} \operatorname{trial}^{4}[F(1,91)=78.14, p<.001]$. Also, responding to each cue did not differ between the $\mathrm{R}$ and the $\mathrm{T}$ trials $(p \mathrm{~s}>.55)$. Thus, with the ES not presented between the $\mathrm{R}$ and the $\mathrm{T}$ trials (in fact, the ES was never presented to this group), as well one might expect, responding to both cues was unaltered between the $\mathrm{R}$ and the $\mathrm{T}$ trials.

Responding to $\mathrm{X}$ and $\mathrm{Y}$ on the $\mathrm{R}$ and the $\mathrm{T}$ trials in Group AER-T is depicted in panel B of Figure 3. These results show that responding to $\mathrm{X}$ and $\mathrm{Y}$ did not differ on the $\mathrm{T}$ trial $(p>.16)$. Also, whereas responding to $\mathrm{X}$ decreased from the $\mathrm{R}$ to the $\mathrm{T}$ trial $[F(1,91)=50.72, p<$ $.001]$, responding to $\mathrm{Y}$ was not affected by the presentation of the $\mathrm{ES}(p>.27)$. These results suggest that the presentation of the ES in Group AER-T did not produce a specific expectation of a reversal in the reinforcement contingencies for Cues X and Y during test but, instead, 

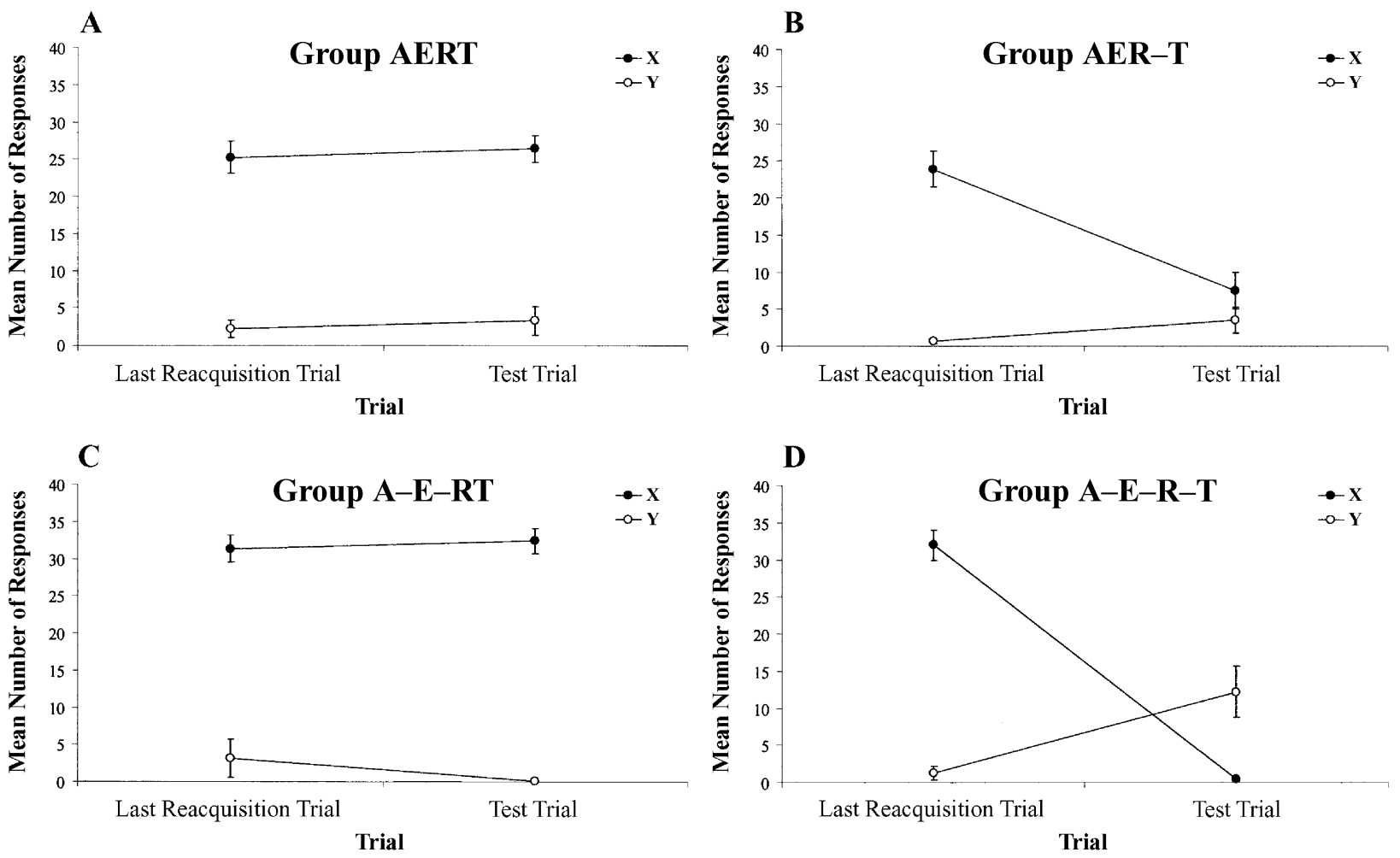

Figure 3. Results of Experiment 3. Mean number of responses to Cues $X$ and $Y$ during the last reacquisition trial and the test trial. Panels A, B, C, and D depict the results of Groups AERT, AER-T, A-E-RT, and A-E-R-T, respectively. Error bars depict standard errors of the means.

generally disrupted responding. In other words, the participants were not sure about the meaning of Cues $\mathrm{X}$ and $\mathrm{Y}$ after the presentation of the ES and, accordingly, reduced the frequency of responding to avoid losing points (remember that, even though $\mathrm{O} 2$ [death of refugees, resulting in loss of points] was never presented during training in this experiment, the participants were instructed about the possibility of the presentation of this outcome).

Panel $\mathrm{C}$ of Figure 3 represents responding to $\mathrm{X}$ and $\mathrm{Y}$ on the R and T trials in Group A-E-RT. Although this group was exposed to the ES between acquisition and extinction and between extinction and reacquisition, the participants in this group had no basis to expect a reversal of the meanings of Cues $\mathrm{X}$ and $\mathrm{Y}$, because the ES had not been presented between reacquisition and testing. Thus, this group was expected to behave similarly to Group AERT. These expectations were fulfilled, as can be seen in the panel and as was supported by the planned comparisons. Responding to $\mathrm{X}$ was stronger than responding to $\mathrm{Y}$ on the $\mathrm{T}$ trial $[F(1,91)=146.50, p<.001]$, and responding to $\mathrm{X}$ and $\mathrm{Y}$ did not vary between the $\mathrm{R}$ and the $\mathrm{T}$ trials ( $p \mathrm{~s}>.18$ ).

Finally, panel D of Figure 3 depicts the critical results of the present experiment: responding to $\mathrm{X}$ and $\mathrm{Y}$ on the $\mathrm{R}$ and T trials in Group A-E-R-T. As can be seen in this panel, responding to $\mathrm{X}$ decreased from the $\mathrm{R}$ to the $\mathrm{T}$ trial $[F(1,91)=218.86, p<.001]$, whereas responding to $\mathrm{Y}$ underwent an increase from the $\mathrm{R}$ to the $\mathrm{T}$ trial $[F(1,91)=$ $20.53, p<.001]$. Moreover, responding to $\mathrm{X}$ during testing was weaker than responding to $\mathrm{Y}[F(1,91)=19.05$, $p<.001]$. Therefore, these results indicate that in Group A-E-R-T, the presentation of the ES before testing effectively yielded an expectation of a reversal of the meaning of Cues X and Y. In other words, the participants expected $\mathrm{Cue} \mathrm{X}$ (which was followed by $\mathrm{O} 1$ during reacquisition) to be followed by $\mathrm{O} 3$ during testing and Cue $\mathrm{Y}$ (which was followed by $\mathrm{O} 3$ during reacquisition) to be followed by $\mathrm{O} 1$ during testing.

In summary, on the basis of the responses to $\mathrm{X}$ and $\mathrm{Y}$ on the $\mathrm{R}$ and $\mathrm{T}$ trials, apparently only the participants in Group A-E-R-T anticipated a reversal of the meaning of the cues during testing. This is not to say that only these participants learned that the ES was a signal for a change in the different cue-outcome relations. The participants in Group A-E-RT could have also learned this signaling property of the ES during training, but they could not anticipate any reversal in the meaning of Cues $\mathrm{X}$ and $\mathrm{Y}$ during testing, due to the absence of the ES between reacquisition and testing. Perhaps the most important comparison here is that between Groups AER-T and A-E-R-T. Both groups were given one presentation of the ES immediately before testing, but only Group A-E-R-T received the ES between the different training phases. In other words, only in Group A-E-R-T could the ES have become a signal 
for a reversal of the meaning of the cues. Clearly, as is shown in Figure 3, responding in groups AER-T (panel B) and A-E-R-T (panel D) followed different patterns. However, since responding to $\mathrm{X}$ decreased from the $\mathrm{R}$ trial to the $\mathrm{T}$ trial in both groups, the critical comparison in these patterns is responding to Y. In Group AER-T, responding to $\mathrm{Y}$ did not change from the $\mathrm{R}$ trial to the $\mathrm{T}$ trial and responding to $\mathrm{Y}$ and $\mathrm{X}$ did not differ, whereas in Group A-E-R-T, responding to $\mathrm{Y}$ on the $\mathrm{T}$ trial was stronger than both responding to $\mathrm{Y}$ on the $\mathrm{R}$ trial and than responding to $\mathrm{X}$ on the $\mathrm{T}$ trial.

A direct comparison, however, between groups AER- $\mathrm{T}$ and $\mathrm{A}-\mathrm{E}-\mathrm{R}-\mathrm{T}$ would be desirable, due to its importance for our present results. Therefore, an additional 2 (group: AER-T vs. A-E-R-T) $\times 2$ (cue: $X$ vs. $Y) \times 2$ (trial: R vs. T) ANOVA on the mean number of responses was performed. This ANOVA detected a marginal effect of group $[F(1,43)=3.48, p=.06]$ and a main effect of trial $[F(1,43)=35.35, p<.001]$. The cue $\times$ trial interaction was also significant $[F(1,43)=114.51, p<.001]$. Most important, the group $\times$ cue $\times$ trial interaction proved significant $[F(1,43)=16.28, p<.001]$. The group $\times$ cue and the group $\times$ trial interactions were not significant $(p s>$ .14). Further analyses were performed comparing responding to $\mathrm{X}$ in each group and showed that on the $\mathrm{R}$ trial, responding was stronger in Group A-E-R-T than in Group AER-T $[F(1,43)=11.46, p<.01]$. However, on the $\mathrm{T}$ trial, responding to $\mathrm{X}$ was weaker in Group A-E-R-T than in Group AER-T $[F(1,43)=5.87, p<$ $.05]$. Therefore, despite the stronger responding to $\mathrm{X}$ by Group A-E-R-T during the $\mathrm{R}$ trial, the expectation of Cue $\mathrm{X}$ being followed by $\mathrm{O} 3$ during the $\mathrm{T}$ trial was higher in Group A-E-R-T than in Group AER-T. Conversely, planned comparisons on responding to $\mathrm{Y}$ in each group showed that responding to this cue did not differ between the groups on the $\mathrm{R}$ trial $(p>.82)$, whereas during the $\mathrm{T}$ trial, responding to $\mathrm{Y}$ was stronger in Group A-E-R-T than in Group AER-T $[F(1,43)=7.17, p<.05]$. Thus, the expectation of Cue $\mathrm{Y}$ being followed by $\mathrm{O} 1$ during testing was higher in Group A-E-R-T than in Group AER-T. These results indicate that the presentation of the ES was differentially processed by the participants in Groups AER-T and A-E-R-T. In Group AER-T, the presentation of the ES merely disrupted responding during testing to Cue X, whereas in Group A-E-R-T, the ES produced an expectation of a reversal in the meaning of the cues. As we will explain in the General Discussion section, these results pose a problem for Bouton's $(1993,1997)$ retrieval theories.

\section{GENERAL DISCUSSION}

In the present series of experiments, we studied the effect of performing contextual changes (Experiment 1) or presenting an ES (i.e., Experiments 2 and 3) on responding to a cue with a prior history of pairings with two different outcomes. Experiment 1 demonstrated the $\mathrm{ABC}$ renewal effect (i.e., Group A-E-T; see Bouton \& Bolles,
1979), as well as an attenuation of the $\mathrm{ABC}$ renewal by performing extinction in multiple contexts (i.e., Group A-E-E-E-T; see Gunther et al., 1998). Experiment 2 replicated the results of Experiment 1, using the presentation of the ES instead of the contextual changes. Also, Experiment 2 showed that responding to the target cue did not recover in a group exposed to the ES only before testing (i.e., Group AE-T, analogous to an AAB renewal design). In Experiment 3, we studied the effect of ES presentation in a reversal learning design including three training phases: acquisition (i.e., $\mathrm{X}-\mathrm{O} 1$ and $\mathrm{Y}-\mathrm{O} 3$ trials), extinction (i.e., $\mathrm{X}-\mathrm{O} 3$ and $\mathrm{Y}-\mathrm{O} 1$ trials), and reacquisition (i.e., $\mathrm{X}-\mathrm{O} 1$ and $\mathrm{Y}-\mathrm{O} 3$ trials). This experiment showed that, in a condition in which the participants were exposed to the ES between all the different phases, the presentation of the ES before testing reversed responding to the cues, relative to reacquisition (i.e., responding to $\mathrm{X}$ decreased, whereas responding to $\mathrm{Y}$ increased).

The results of Experiment 1 can be fully explained by a straightforward extension of Bouton's (1993) theory. This account explains the recovery of responding observed in Group A-E-T in terms of a renewal of the response due to performance of the acquisition, extinction, and test phases in different contexts. This kind of renewal (i.e., $\mathrm{ABC}$ renewal) was thus attenuated in Group A-E-E-E-T due to extinction training in different contexts, which presumably facilitated priming of the inhibitory association in the context of test because a larger number of the cues in the extinction contexts were present in the test context (Gunther et al., 1998). However, the results of Experiment 2 raise more problems for this account. The proposed extension of Bouton's theory (i.e., the ES as a priming stimulus for the subsequently trained associations) predicted that the presentation of the ES between acquisition and extinction (i.e., Groups A-ET, A-E-T, and A-E-E-E-T) would turn the ES into a priming stimulus for the subsequently trained $\mathrm{X}-\mathrm{O} 3$ association. Because the $\mathrm{X}-\mathrm{O} 3$ association was already primed before testing, presenting the ES between the extinction and the test phases should be irrelevant to responding to $\mathrm{X}$ at testing. Thus, according to this extension of Bouton's model, the presentation of the ES should have been unable to produce recovery of responding in any group, including Group A-E-T, the group in which recovery was in fact observed.

The signal hypothesis can readily explain the results of both Experiments 1 and 2. According to this hypothesis, when the contextual change (Experiment 1) or the presentation of the ES (Experiments 2 and 3) takes place between the acquisition and the extinction phases, the participants learn that this change in the environmental cues predicts a change in the meaning of the target cue. Therefore, when this manipulation is performed again before testing, the participants anticipate a new change in the meaning of the target cue. Thus, two complementary processes take place according to this hypothesis. First, a predictive relationship between the manipulation and the change in the cue-outcome relation is learned. This manipulation, consisting of a context change (Ex- 
periment 1), the presentation of an ES (Experiments 2 and 3), or even manipulations that are different from those used in the present experiments (e.g., time intervals or, in associative learning experiments with humans, the presentation of instructions; see Matute, Vegas, \& De Marez, 2002, Experiment 4) causes the participants to anticipate a reversal of the cue-outcome relationship. It is important to note that these changes in the cueoutcome relationship are both cue specific and outcome specific. That is, the manipulation produces an expectation of a change in the meaning only of cues with which it has been paired, and this cue's meaning is alternated exclusively between the outcomes previously paired with the cue. In Experiments 1 and 2, the target cue, X, was first paired with $\mathrm{O} 1$ (acquisition) and then with $\mathrm{O} 3$ (extinction). Also, the discriminative cue, Y, was paired with $\mathrm{O} 2$ (i.e., the aversive outcome) during acquisition. In Group $\mathrm{A}-\mathrm{E}-\mathrm{T}$, the interphase manipulation before testing produced a recovery of responding, showing that Cue X was expected to be followed by O1. If the participants had assumed that the manipulation signaled an interchange of outcomes between Cues X and Y, responding to $\mathrm{X}$ would not have been recovered (i.e., since $\mathrm{X}$ would then be expected to be followed by $\mathrm{O} 2$ ).

The signal hypothesis can explain the recovery of responding observed in Group A-E-T in Experiment 2, and why responding did not recover in Group $\mathrm{AE}-\mathrm{T}$ in Experiment 2. The latter group was not able to learn that the presentation of the ES was a predictor of a change in the cue-outcome relationship. If we assume that this rule can be also disconfirmed when the manipulation occurs during extinction (i.e., a situation in which the manipulation is not followed by any change in the cue-outcome relation), the attenuation of response recovery observed in Group A-E-E-E-T (Experiments 1 and 2) can be explained. Despite the fact that the participants in this group acquired the rule that outcomes reverse with occurrences of the manipulation between acquisition and extinction, these participants had no reason to expect that the presentation of the manipulation before test would predict a change in the cue-outcome relation. The reduction in the value of the signal in this group was presumably due to learning, during the two extinction phase presentations of the manipulation, that the manipulation no longer predicted a change in the cue-outcome relation.

The results of Experiment 3 also support the signal hypothesis and present problems for the extension of Bouton's (1993) theory. The critical results of this experiment are those for Group A-E-R-T, which received one presentation of the ES between each of the treatment phases (i.e., acquisition, extinction, reacquisition, and testing). In this group, the presentation of the ES just prior to testing appears to have produced an expectation of a reversal of the cue-outcome relations (i.e., $\mathrm{X}$ being followed by $\mathrm{O} 3$ and $\mathrm{Y}$ by $\mathrm{O} 1$ ) during testing. This expectation of reversal of the cue-outcome relations was not observed in the groups that received the ES only between acquisition and extinction and between extinction and reacquisition (i.e., Group A-E-RT) or only between reacquisition and test (i.e., Group AER-T). These results especially raise problems for the extension of Bouton's (1993) theory, in that this theory predicts a recovery of responding to both $\mathrm{X}$ and $\mathrm{Y}$ in Groups AER-T and A-E-R-T, due to the presentation of the ES before testing, causing impaired retrieval of the $\mathrm{X}-\mathrm{O} 3$ and $\mathrm{Y}-\mathrm{O} 3$ inhibitory associations. However, Bouton's (1997) theory predicted that, in both Groups AER-T and A-ER-T, presenting the ES before testing should have disrupted retrieval of the second-learned associations (i.e., $\mathrm{X}-\mathrm{O} 1$ and $\mathrm{Y}-\mathrm{O} 3$ ), thereby producing a recovery of responding to $\mathrm{X}$ and reducing responding to $\mathrm{Y}$. Nevertheless, because the impaired retrieval of the second-learned associations was already produced before testing by the training of the $\mathrm{X}-\mathrm{O} 1$ and $\mathrm{Y}-\mathrm{O} 3$ associations during reacquisition, the presentation of the ES before testing should have had no effect on responding to the cues. In contrast, the signal hypothesis can account for the results of this experiment in a simple fashion. Regardless of whether the specific change in the cue-outcome relation was signaled by the $\mathrm{ES}$ (e.g., from $\mathrm{X}-\mathrm{O} 1$ to $\mathrm{X}-\mathrm{O} 3$ or from $\mathrm{Y}-\mathrm{O} 3$ to $\mathrm{Y}-\mathrm{O} 1$ ), the expectancy of a reversal in the meaning of cues $\mathrm{X}$ and $\mathrm{Y}$ in Group A-E-R-T (but not in Group AER-T) is consistent with this hypothesis, in which ES signaled a change in the meaning of the cues or, in other words, of the $\mathrm{X}-\mathrm{O}$ and $\mathrm{Y}-\mathrm{O}$ relations.

In sum, the present results, especially those in Experiment 3 , challenge the comprehensiveness of the current best-candidate theory of interference between outcomes (Bouton, 1993). These results suggest that humans are able to develop rules during the occurrence of contextual manipulations (Experiment 1) or during the presentation of unexpected stimuli (i.e., ESs, Experiments 2 and 3) on the basis of very few training trials and that these rules can modulate responding to the cues. Although it is quite risky to extrapolate the present results to conditioning experiments with nonhuman animals, this possibility should be entertained. Further research is necessary in order to ascertain whether the present results reflect a general process or, by contrast, are species and/or preparation specific. In any case, the possibility of humans (and perhaps also nonhuman animals) being able to learn to anticipate a reversal in the cue-outcome contingencies on the basis of context changes or the presentation of unexpected stimuli should not be viewed as incompatible with Bouton's (1993) hypothesis on the contextual dependency of inhibitory associations. The inability of the signal hypothesis to explain AAB renewal (Bouton \& Ricker, 1994) and spontaneous recovery (Pavlov, 1927), effects that are straightforwardly explained by Bouton's theory, together with the inability of Bouton's theory to explain the results of our Experiment 3, suggest that perhaps both mechanisms operate simultaneously in some cases and individually in others. For example, in the ABA and $\mathrm{ABC}$ renewal, the effect of both mechanisms on responding to the cue could summate, as a consequence of impaired retrieval of the second-learned association in the 
context of testing (Bouton) and also a reversal in the cue-outcome relationship being anticipated due to the context change performed immediately before testing (signal hypothesis). The latter possibility would explain why response recovery is usually stronger in $\mathrm{ABA}$ and $\mathrm{ABC}$ renewal designs, relative to the $\mathrm{AAB}$ renewal (see Bouton \& Ricker, 1994, for a discussion), in which the reversal in the cue-outcome relationship cannot be anticipated before testing.

\section{REFERENCES}

Bouton, M. E. (1993). Context, time, and memory retrieval in the interference paradigms of Pavlovian learning. Psychological Bulletin, 114, 80-99.

BOUTON, M. E. (1994). Conditioning, remembering, and forgetting. Journal of Experimental Psychology: Animal Behavior Processes, 20, 219-231.

BoUTON, M. E. (1997). Signals for whether versus when an event will occur. In M. E. Bouton \& M. S. Fanselow (Eds.), Learning, motivation, and cognition: The functional behaviorism of Robert C. Bolles (pp. 385-409). Washington, DC: American Psychological Association.

Bouton, M. E., \& Bolles, R. C. (1979). Contextual control of the extinction of conditioned fear. Learning \& Motivation, 10, 445-466.

Bouton, M. E., \& King, D. A. (1983). Contextual control of the extinction of conditioned fear: Tests for the associative value of the context. Journal of Experimental Psychology: Animal Behavior Processes, 9, 248-265.

BoUTON, M. E., \& NELSON, J. B. (1998). Mechanisms of feature-positive and feature-negative discrimination learning in an appetitive conditioning paradigm. In N. A. Schmajuk \& P. C. Holland (Eds.), Occasion setting: Associative learning and cognition in animals (pp. 69-112). Washington, DC: American Psychological Association.

Bouton, M. E., \& Ricker, S. T. (1994). Renewal of extinguished responding in a second context. Animal Learning \& Behavior, 22, 317324.

Chelonis, J. J., Calton, J. L., Hart, J. A., \& Schachtman, T. R. (1999). Attenuation of the renewal effect by extinction in multiple contexts. Learning \& Motivation, 30, 1-14.

Chiszar, D. A., \& Spear, N. E. (1965). Stimulus change, reversal learning, and retention in the rat. Journal of Comparative \& Physiological Psychology, 69, 190-195.

Dickinson, A., \& BURKe, J. (1996). Within-compound associations mediate the retrospective revaluation of causality judgements. Quarterly Journal of Experimental Psychology, 49B, 60-80.

Escobar, M., Arcediano, F., \& Miller, R. R. (in press). Disruption of latent inhibition by interpolation of task-irrelevant stimulation between preexposure and conditioning. Learning \& Behavior.

Escobar, M., Pineño, O., \& Matute, H. (2002). A comparison between elemental and compound training of cues in retrospective revaluation. Animal Learning \& Behavior, 30, 228-238.

García-Gutiérrez, A., \& Rosas, J. M. (2003). Empirical and theoretical implications of additivity between reinstatement and renewal after interference in causal learning. Behavioural Processes, 63, 2131.

Gunther, L. M., Denniston, J. C., \& Miller, R. R. (1998). Conducting exposure treatment in multiple contexts can prevent relapse. Behavior Research \& Therapy, 36, 75-91.

Harris, J. A., Jones, M. L., Bailey, G. K., \& Westbrook, R. F. (2000). Contextual control over conditioned responding in an extinction paradigm. Journal of Experimental Psychology: Animal Behavior Processes, 26, 174-185.

MACKINTOSH, N. J. (1975). A theory of attention: Variations in the as- sociability of stimuli with reinforcement. $\underline{\text { Psychological Review, }} \underline{\mathbf{8 2}}$ 276-298.

Matute, H., Vegas, S., \& De Marez, P. J. (2002). Flexible use of recent information in causal and predictive judgments. Journal of Experimental Psychology: Learning, Memory, \& Cognition, 28, 714725

MilleR, R. R., \& Matzel, L. D. (1988). The comparator hypothesis: A response rule for the expression of associations. In G. H. Bower (Ed.), The psychology of learning and motivation (Vol. 22, pp. 5192). San Diego: Academic Press.

Pavlov, I. P. (1927). Conditioned reflexes. (G.V. Anrep, Trans.). London: Oxford University Press.

Pearce, J. M. (1987). A model for stimulus generalization in Pavlovian conditioning. Psychological Review, 94, 61-73.

Pearce, J. M., \& Hall, G. (1980). A model for Pavlovian learning: Variations in the effectiveness of conditioned but not of unconditioned stimuli. Psychological Review, 87, 532-552.

PineÑo, O., \& MATUTE, H. (2000). Interference in human predictive learning when associations share a common element. International Journal of Comparative Psychology, 13, 16-33.

Pineño, O., Ortega, N., \& Matute, H. (2000). The relative activation of the associations modulates interference between elementally trained cues. Learning \& Motivation, 31, 128-152.

ResCorla, R. A., \& WAGNER, A. R. (1972). A theory of Pavlovian conditioning: Variations in the effectiveness of reinforcement and nonreinforcement. In A. H. Black \& W. F. Prokasy (Eds.), Classical conditioning II: Current research and theory (pp. 64-99). New York: Appleton-Century-Crofts.

Rosas, J. M., VILA, J., Lugo, M., \& LóPez, L. (2001). Combined effects of context change and retention interval on interference in causality judgments. Journal of Experimental Psychology: Animal Behavior Processes, 27, 153-164.

RUDY, J. W., ROSEnBERG, L., \& SANDEll, J. H. (1977). Disruption of a taste familiarity effect by novel exteroceptive stimulation. Journal of Experimental Psychology: Animal Behavior Processes, 3, 26-36.

Van Hamme, L. J., \& Wasserman, E. A. (1994). Cue competition in causality judgments: The role of nonpresentation of compound stimulus elements. Learning \& Motivation, 25, 127-151.

Vila, J., Romero, M., \& Rosas, J. M. (2002). Retroactive interference after discrimination reversal decreases following temporal and physical context changes in human subjects. Behavioural Processes, $\mathbf{5 9}$ 47-54.

WAGNER, A. R. (1981). SOP: A model of automatic memory processing in animal behavior. In N. E. Spear \& R. R. Miller (Eds.), Information processing in animals: Memory mechanisms (pp. 5-47). Hillsdale, NJ: Erlbaum.

\section{NOTES}

1. We will refer to the fifth context as "F" in order to avoid confusion with our referring to the extinction phase as "E" in the group names.

2. The preparation used in each of the present experiments can be downloaded from http://www.opineno.com/task.htm.

3. A difference score (i.e., number of responses during test minus number of responses prior to test) could also have been used. However, the FR variable has the advantage of rescaling the scores to a range of 0 to 1 , which reduces within-group variability due to inherently high and low responders.

4. The comparison between responding to $\mathrm{X}$ and $\mathrm{Y}$ in the $\mathrm{R}$ trial is redundant here because the data selection criteria ensured a higher responding to $\mathrm{X}$ than to $\mathrm{Y}$ in the data of all the participants, in order for the data to be accepted.

(Manuscript received September 4, 2003; revision accepted for publication January 26, 2004.) 